\title{
Opere citate
}

\section{Fonti}

Acta Henrici VII Imperatoris Romanorum et Monumenta quaedam alia Medii Aevi, a cura di G. Doenniges, Berlin 1839.

Acta Henrici VII Romanorum Imperatoris et monumenta quaedam alia suorum temporum historiam illustrantia, a cura di F. Bonaini, Firenze 1877 (rist. anastica Aalen 1970).

Acta Imperii Angliae et Franciae ab A. 1267 ad A. 1313: Dokumente Vornehmlich zur Geschichte der Auswärtigen Beziehungen Deutschlands in Ausländischen Archiven, a cura di F. Kern, Tübingen 1911.

Die Aktenstücke zum Frieden von S. Germano 1230, MGH EE., Epistole selectae, IV, a cura di K. Hampe, Berlin 1926.

Annales Aretinorum, Maiores et Minores, con appendice di altre croniche e di documenti, a cura di A. Bini, G. Grazzini, RIS², XXIV, 1, Città di Castello 1909.

Annales Caesenates, a cura di E. Angiolini, Roma 2003.

Arnaldi de Villanova, Tractatus de tempore adventus Antichristi. Ipsius et aliorum scripta coæva, a cura di J. Perarnau, Barcelona 2014.

Augustinus Hipponensis, In Evangelium loannis tractatus CXXIV, PL, XXXV: on-line <https:// www.augustinus.it/latino/commento_vsg/index.htm>.

Augustinus Hipponensis, De Genesi ad litteram, a cura di J. Zycha, CSEL XXVIII/4 Vindobonae 1894.

E. Batzer, Zur Kenntnis der Formularsammlung des Richard von Pofi, Heidelberg 1910.

E. Baluze, Vitae paparum avenionensium, nouvelle édition par Guillaume Mollat, Paris 18771968.

Bene da Firenze, Candelabrum, a cura di G. C. Alessio, Padova 1983.

The Oxford Bible Commentary, a cura di J. Barton, J. Muddiman, Oxford 2001.

G. Boccaccio, Decameron, a cura di V. Branca, in Tutte le opere di G. Boccaccio, IV, Milano 1976.

G. Boccaccio, Esposizioni sopra la Comedia di Dante, a cura di G. Padoan, in Tutte le opere di Giovanni Boccaccio, VI, Milano 1965.

G. Boccaccio, Genealogie deorum gentilium, a cura di V. Zaccaria, in Tutte le opere di Giovanni Boccaccio, VII-VIII, Milano 1998.

G. Boccaccio, Trattatello in laude di Dante, a cura di P. G. Ricci, in Tutte le opere di Giovanni Boccaccio, III, Milano 1974, pp. 423-538.

G. Boccaccio, Trattatello (I ${ }^{\mathrm{a}}$ red.), in NECOD, IV, Le vite di Dante dal XIV al XVI secolo. Iconografia dantesca, a cura di M. Berté, M. Fiorilla, S. Chiodo, I. Valente, Roma 2017, pp. 28-120.

G. Boccaccio, Trattatello (II ${ }^{\mathrm{a}}$ red.), in NECOD, IV, Le vite di Dante dal XIV al XVI secolo. Iconografia dantesca, a cura di M. Berté, M. Fiorilla, S. Chiodo, I. Valente, Roma 2017, pp. 121-154.

Bono Giamboni, Il libro de' vizî e delle virtudi e ll trattato di virtú e di vizî, a cura di C. Segre, Torino 1968.

Bonus Lucensis, Cedrus Libani, a cura di G. Vecchi, Modena 1963.

V. Borghini, Discorsi, a cura di D. M. Manni, Milano 1808.

L. Bruni, Vita di Dante, in Opere letterarie e politiche, a cura di P. Viti, Torino 1996, pp. $536-$ 552.

O Open Access. () 2020 published by De Gruyter. (c) BY This work is licensed under the Creative Commons Attribution 4.0 International License (CC BY 4.0).

https://doi.org/10.1515/9783110590661-028 
L. Bruni, Vita di Dante, a cura di M. Berté, in NECOD, VII, Roma 2017, pp. 213-248.

M. Campanelli, Le sentenze contro i Bianchi fiorentini del 1302. Edizione critica, in «Bullettino dell'istituto storico italiano per il Medio Evo», 108 (2006), pp. 187-377.

Carteggio dantesco del duca di Sermoneta con Giambattista Giuliani, Carlo Witte, Alessandro Torri, ed altri insigni dantofili, Milano 1883.

Chronicon Parmense ab anno MXXXVIII usque ad annm MCCCXXXVIII, a cura di G. Bonazzi, RIS², 9/9, Città di Castello 1902.

Dantis Alagherii Monarchiae liber et Epistolae ex codice Vaticano Palatino latino 1729 phototypice expressa, praefatus est F. Schneider, Romae 1930.

D. Compagni, Cronica, a cura di D. Cappi, Roma 2000.

D. Compagni, La Cronica di Dino Compagni delle cose occorrenti ne' tempi suoi, a cura di I. Del Lungo, RIS², 9/2, Città di Castello 1913.

Conciliorum Oecumenicorum Decreta, a cura di G. Alberigo, G. L. Dossetti, P. P. Joannou, C. Leonardi, P. Prodi, Bologna $1991^{2}$.

I consigli della Repubblica Fiorentina, a cura di B. Barbadoro, Bologna 1921.

Constantiae imperatricis et reginae Siciliae diplomata (1195-1198), Codex diplomaticus Regni Siciliae, ser. 2: Diplomata regum e gente suevorum, edd. C. Bruhl, F. Giunta, 1/2, KölnWien 1983.

Le consulte della Repubblica fiorentina dall'anno MCCLXXX al MCCXCVIII, a cura di A. Gherardi, Firenze 1896-1898.

Corpus Chronicorum Bononensium, a cura di A. Sorbelli, RIS², 18/1, Città di Castello 1938. Corpus iuris canonici, I, a cura di Ae. Friedberg, Lipsiae 1879.

Cronache senesi, a cura di A. Lisini, F. lacometti, Torino 1969.

Diplomatario de la reina Urraca de Castilla y León (1109-1126), ed. C. Monterde Albiac, Zaragoza 1995.

Epistole et dictamina Clementis pape quarti, a cura di M. Thumser, MGH, 2007, <http:// www.mgh.de/datenbanken/epistolae/clemens-iv/>.

Ex rerum Anglicarum scriptoribus saeculi XIII, a cura di F. Liebermann, MGH SS (in folio), XXVIII, Hannover 1888.

Magistri Guidonis Fabe Rota nova: ex codice manuscripto oxoniensi New College 255 nunc primum prodit, a cura di A. Campbell, V. Pini, A. Saiani, Bologna 2000.

G. Faba, Summa artis dictaminis, a cura di A. Gaudenzi, in «ll Propugnatore», 3 (1890), vol. 13-14 pp. 287-338, vol. 16-17, pp. 345-393.

E. Faral, Les arts poétiques du XII ${ }^{e}$ et du XIII ${ }^{e}$ siècle: recherches et documents sur la technique littéraire du Moyen Age, Paris 1924.

Ferreto de' Ferreti, Historia rerum in Italia gestarum ab anno MCCL ad annum usque MCCCXVIII, in Le opere di Ferreto de' Ferreti vicentino, a cura di C. Cipolla, Roma 1908.

E. Fleuchaus, Die Briefsammlung des Berard von Neapel, München 1998.

Fontes Franciscani, a cura di E. Menestò, S. Brufani et al., Santa Maria degli Angeli-Assisi 1995.

Fontes rerum Austriacarum, 2. Diplomataria et acta, VI.2: Das Stiftungs-buch des Klosters St. Bernhard, ed. H. J. Zeibig, Wien 1853.

Francesco da Barberino, Reggimento e costumi di donna, ed. critica a cura di G. E. Sansone, Roma 1995.

C. Ghirardacci, Della historia di Bologna, parte prima, Bologna 1596.

Giordano da Osnabrück, Tractatus super Romano Imperio, in MGH, SS, Staatschriften des Spateren Mittelatlers, pp. 94-148. 
Giovanni da Cermenate, Historia lohannis de Cermenate notarii mediolanensis, a cura di L. A. Ferrai, Roma 1889.

Guglielmo di Ockham, Dialogus, in M. Goldast, Monarchia S. Romani Imperii, II, Francofordiae 1614 (rist. anast. Graz 1960).

Guglielmo da Pastrengo, De viris illustribus et de originibus, a cura di G. Bottari, Padova 1991.

E. Heller, Die Ars dictandi des Thomas von Capua, in «Sitzungsberichte der Heidelberger Akademie der Wissenschaften. Philosophisch-historische Klasse», 1928-1929.

Henrici VII Constitutiones, a cura di J. Schalm, in MGH, Constitutiones et acta publica imperatorum et regum, 4, 1 (1298-1311), Hannover-Leipzig 1906.

Henrici VII Constitutiones, a cura di J. Schalm, MGH, Constitutiones et acta publica imperatorum et regum, 4, 2 (1312-1313), Hannover-Leipzig 1909-11.

Hieronymus, Contra Rufinum, in S. Hieronymi presbyteri Opera. Pars Prima. Opera polemica, I. Contra Rufinum, a cura di P. Lardet, Turnholti 1982.

Jacobus de Ravanis, Lectura super prima [-secunda] parte Codicis domini Justiniani, Paris, 1519.

Jean XXII, Lettres communes, a cura di G. Mollat, Paris 1904-1947.

Jean XXII, Lettres secrètes et curiales relatives à la France, a cura di A. Coulon, S. Clémencet, Paris 1900-1972.

Joachim von Fiore, Concordia Novi ac Veteris Testamenti, hrsg. von A. Patschovsky, Teile 1-4, Wiesbaden 2017.

Die Konstitutionen Friedrichs II. für das Königreich Sizilien, MGH, LL, Constitutiones et acta publica imperatorum et regum, 2, Inde ab a. MXCXVIII. usque ad a. MCCLXXII, supplementum, a cura di W. Stürner, Hannover 1996.

Il Libro del chiodo, riproduzione in fac-simile con edizione critica, a cura di F. Klein, Firenze 2004.

Marchionne di Coppo Stefani, Cronaca fiorentina, a cura di N. Rodolico, Città di Castello 1903.

MGH, LL, Constitutiones et acta publica imperatorum et regum, 2, Inde ab a. MXCXVIII. usque ad a. MCCLXXII, a cura di L. Weiland, Hannover 1896.

MGH, LL, Constitutiones et acta publica imperatorum et regum, 3, Inde ab a. MCCLXXIII. usque ad a. MCCXCVIII, a cura di I. Schwalm, Hannover 1904-1906.

MGH, LL, Constitutiones et acta publica imperatorum et regum, 4, Inde ab a. MCCXCVIII usque ad a. MCCCXIII, a cura di I. Schwalm, Hannover 1906.

MGH, LL, Constitutiones et acta publica imperatorum et regum, 6, Inde ab a. MCCCXV. usque ad a. MCCCXXX, a cura di I. Schwalm, Hannover 1927.

G. Manetti, Vita Dantis in Biographical Writings, eds. S. U. Baldassarri, R. Baghemil, Cambridge (MA)-London 2003, pp. 2-61.

Mini de Colle Vallis Elsae, Epistolae, a cura di F. Luzzati Laganà, Roma 2010.

G. B. Mittarelli, Bibliotheca codd. Mss. Monasterii S. Michaelis Venetiarum prope Muranum, Venezia 1779.

A. Mussato, De gestis Heinrici VII Caesaris historia augusta, RIS X, Milano 1727.

Nicola da Rocca, Epistolae, a cura di F. Delle Donne, Firenze 2003.

Nicolai episcopi Botrontinensis Relatio de itinere Italico Henrici VII imperatori ad Clementem $V$ papam, in E. Baluze, Vitae paparum Avenionensium, a cura di G. Mollat, vol. III, Paris 1921, pp. 491-561 (on-line: <http://baluze.univ-avignon.fr/>).

Oraculum Angelicum Cyrilli, nebst dem Kommentar des PseudoJoachim, herausgegeben von P. Piur, in K. Burdach, Von Mittelalter zur Reformation. Forschungen zur Geschichte der deutschen Bildung, zweiter band, vierter teil, Berlin 1912, pp. 221-343. 
The Parisiana Poetria of John of Garland, ed. T. Lawler, New Haven 1974 (alternativamente ed. in G. Mari, Poetria magistri Johannis anglici de arte prosayca metrica et rithmica, in «Romanische Forschungen», 13/3 [1902], pp. 883-965).

"Quaestio de Potestate Papae (Rex Pacificus)": An Enquiry into the Power of the Pope: A Critical Edition and Translation, a cura di R. W. Dyson, Lewiston (NY) 1999.

F. Petrarca, Il Bucolicum Carmen e i suoi commenti inediti, a cura di A. Avena, Padova 1906 (= rist. Bologna 1969).

F. Petrarca, Le Familiari, a cura di V. Rossi, Firenze 1933-1942.

Petrus Blesensis, Epistolae, in PL, 207, coll. 1-558.

Petrus de Vinea, Epistolae, a cura di J. R. Iselin (Iselius), Basileae 1740 (ristampa anastatica, con Einführung di H. M. Schaller, Hildesheim 1991).

L'Epistolario di Pier della Vigna, edizione, traduzione italiana, introduzione e commento a cura di A. Boccia, E. D’Angelo, T. De Angelis, F. Delle Donne, R. Gamberini, Ariano Irpino 2014.

Piccola antologia della Bibbia volgata con introduzione e note per cura di Ermenegildo Pistelli, con dodici tavole e in appendice alcune epistole di Dante e del Petrarca secondo il programma del liceo moderno, Firenze 1915.

P. Pieri, Croniche della città di Firenze, a cura di C. Coluccia, Lecce-Rovato 2013.

W. Preger, J. H. Reinkens, Die Verträge Ludwigs des Baiern mit Friedrich dem Schönen in den Jahren 1325 und 1326: mit J. H. Reinkens Auszügen aus Urkunden des vatikanischen Archivs von 1325-1334, in «Abhandlungen der Historischen Klasse der KöniglichBayerischen Akademie der Wissenschaften», 17 (1886), pp. 103-338.

W. Preger, Die Anfänge des kirchenpolitischen Kampfes unter Ludwig dem Bayern: mit Auszügen aus Urkunden des vatikanischen Archivs von 1315-1324, in «Abhandlungen der Historischen Klasse der Königlich-Bayerischen Akademie der Wissenschaften», 16/2 (1882), pp. 113-284.

Delle poesie di Antonio Pucci celebre versificatore, in I. Di San Luigi, Delizie degli eruditi toscani, vol. V, Firenze 1774.

Il "quaternus rogacionum" del notaio Bongiovanni di Bonandrea (1308-1320), a cura di D. Rando, M. Motter, Bologna 1997.

Il Quinternone di Ascoli Piceno, a cura di G. Borri, Spoleto 2009.

Regesta Imperii, V. Die Regesten des Kaiserreichs unter Philipp, Otto IV, Friedrich II, Heinrich (VII), Conrad IV, Heinrich Raspe, Wilhelm und Richard. 1198-1272, a cura di J. Ficker, Innsbruck 1882.

Regesta Imperii VI.2, Die Regesten des Kaiserreiches unter Rudolf, Adolf, Albrecht, Heinrich VII. 1273-1313, 2. Die Regesten des Kaiserreiches unter Adolf von Nassau. 1291-1298, a cura di V. Samanek, Wien 1948.

Regesta Imperii VI.4, Heinrich VII. 1288/1308-1313, lief. 1: 1288/1308-August 1309, a cura di K.-U. Jäschke, P. Thorau, Wien-Weimar-Köln 2006.

Regesten der Pfalzgrafen am Rhein, a cura di A. Koch, E. Winkelmann, I: 1214-1400, Innsbruck 1894.

Les registres de Boniface VIII, a cura di G. Digard et M. Faucon, Paris, 1884-1931.

La reina doña Urraca (1109-1126). Cancílleria y colección diplomática, ed. I. Ruiz Albi, León 2003.

Hieronymi Rubei Historiarium Ravennatum libri decem hac altera editione libro undecimo aucti, et multiplici, insignisque antiquitatis historia amplissime locupletati ..., Venetiis 1589. 
Girolamo Rossi, Storie ravennati, trad. e cura di M. Pierpaoli, pref. di A. Vasina, Ravenna 1996.

Salimbene de Adam, Cronica, a cura di G. Scalia, Bari 1966.

Coluccio Salutati, Epistolario, a cura di F. Novati, Roma 1891-1911.

Coluccio Salutati, Political Writings, a cura di S. U. Baldassarri e R. Bagemihl, Cambridge (MA)-London 2014.

Serie dei consoli e dei podestà del Comune di Siena, in Archivio del Consiglio generale del Comune di Siena. Inventario, Roma 1952.

Una silloge epistolare della seconda metà del XIII secolo. I "dictamina» provenienti dall'Italia meridionale del ms. Paris, Bibl. Nat. Lat. 8567, ed. a cura di F. Delle Donne, Firenze 2007.

Publilii Syri Sententiae, ad fidem codicum optimorum primum recensuit E. Woelfflin, Lipsiae 1869.

I. Hijmans-Tromp, La "Sommetta" falsamente attribuita a Brunetto Latini, in «Cultura Neolatina», 59 (1999), pp. 177-243.

Statuti della Repubblica fiorentina, ed. a cura di R. Caggese, nuova ed. a cura di G. Pinto, F. Salvestrini, A. Zorzi, vol. II, Statuto del Podestà dell'anno 1325, Firenze 1999.

Storie Pistoresi (MCCC-MCCCXLVIII), a cura di S. A. Barbi, Città di Castello 1927.

Testi fiorentini del Dugento e dei primi del Trecento, con introduzione, annotazioni linguistiche e glossario, a cura di A. Schiaffini, Firenze 1926 (rist. 1954).

Die Briefsammlung des Thomas von Capua, a cura di J. Frohmann, M. Thumser, MGH, 2011, $\langle$ www.mgh.de/datenbanken/thomas-von-capua〉.

J.-P. Torrell, Théorie de la prophétie et philosophie de la connaissance aux environs de 1230. La contribution d'Hugues de Saint-Cher (ms Douai 434, Quest. 481), édition critique avec introduction et commentaire, Leuven, 1977.

Thomae Aquinatis, Catena aurea in quatuor Evangelia, <http://docteurangelique.free.fr/ bibliotheque/ecriture/catenaaureajean.htm>.

Thomas von Capua, Ars dictaminis, in E. Heller, Die Ars dictandi des Thomas von Capua, in «Sitzungsberichte der Heidelberger Akademie der Wissenschaften. Philosophischhistorische Klasse», 1928-1929.

Three Royalist Tracts, 1296-1302, ed. and trans. R. W. Dyson, Durham-Sterling 1999.

P. Toynbee, Appendix C, in Dantis Alagherii Epistolae. Letters of Dante, ed. P. Toynbee, Oxford 1920.

P. Toynbee, Dante's Letter to the Emperor Henry VII: Critical Text, in «The Modern Language Review», 10 (1915), pp. 64-72.

P. Toynbee, The S. Pantaleo Text of Dante's Letters to the Emperor Henry VII, and to the Princes and Peoples of Italy, in «The Modern Language Review», 7 (1912), pp. 208-224.

P. Toynbee, The Vatican Text (Cod. Vat.-Palat. Lat. 1729) of the Letters of Dante, in «The Modern Language Review», 7 (1912), pp. 1-39.

P. Toynbee, The Venetian Text (Cod. Marc. Lat. XIV, 115) of Dante's Letter to the Emperor Henry VII, in «The Modern Language Review», 7 (1912), pp. 433-440.

Tyrannii Rufini Apologia adversus Hieronymum, in Tyrannii Rufini Opera, a cura di M. Simonetti, Turnhout 1961, pp. 29-123.

Uguccione da Pisa, Derivationes, a cura di E. Cecchini et al., Firenze 2004.

Die Urkunden der lateinischen Könige von Jerusalem, a cura di H. E. Mayer, III, MGH, Hannover 2010.

Die Urkunden Heinrich Raspes und Wilhelms von Holland 1246-1252, a cura di D. Hägermann et al., MGH, Hannover 1989. 
Die Urkunden Lothars III. und der Kaiserin Richenza, a cura di E. von Ottenthal e H. Hirsch, in MGH, DD, VIII, Berlin 1927.

Die Urkunden und Briefe der Markgräfin Mathilde von Tuszien, a cura di E. e W. Goez, in MGH, DD, Laienfürsten- und Dynasten-Urkunden der Kaiserzeit, II, Hannover 1998.

M. Vescovo, La Gemma purpurea di Guido Faba. Edizione critica e commento, tesi di laurea magistrale in Scienze dell'Antichità, Università Ca' Foscari Venezia, relatore

A. Montefusco, Venezia 2019.

Filippo Villani, Expositio seu Comentum super "Comedia" Dantis Allegherii, a cura di

S. Bellomo, Firenze 1989.

Giovanni Villani, Cronica, a cura di P. Massai, I. Moutier, Firenze 1823.

Giovanni Villani, Nuova Cronica, a cura di G. Porta, Parma 1991.

La visita pastorale del 1424 compiuta nel Casentino dal vescovo Francesco da Montepulciano (1414-1433), a cura del sac. F. Coradini, Anghiari 1941.

E. A. Winkelmann, Acta imperii inedita saeculi XIII. Urkunden und Briefe zur Geschichte des Kaiserreichs und des Königreichs Sizilien (1198-1273), Innsbruck 1880 (rist. anast. Aalen 1964).

\section{Studi}

D. Abulafia, Genova angioina, 1318-1335: gli inizi della signoria di Roberto re di Napoli, in Mediterranean Encounters: Economic, Religious, Political, 1100-1550, Aldershot 2000.

D. Abulafia, The Western Mediterranean Kingdoms 1200-1500: the Struggle for Domination, London-New York 1997 (trad. it. I regni del Mediterraneo occidentale dal 1200 al 1500. La lotta per il dominio, Roma-Bari 2006).

G. Agamben, Il regno e la gloria: Per una genealogia teologica dell'economia e del governo, Torino 2009.

Alfabetismo e cultura scritta, a cura di A. Bartoli Langeli, A. Petrucci, in «Quaderni storici», XIII (1978), 38.

Alfabetismo e cultura scritta nella storia della società italiana. Atti del seminario (Perugia, 29-30 marzo 1977), Perugia 1978.

G. C. Alessio, I trattati di grammatica e retorica e i classici, in I classici e l'Università umanistica. Atti del Convegno di Pavia, 22-24 novembre 2001, a cura di L. Gargan, M. P. Mussini Sacchi, Messina 2006, pp. 161-194.

G. C. Alessio, L'ars dictaminis nel Quattrocento italiano: eclissi o persistenza?, in «Rhetorica», 19 (2001), pp. 155-173.

G. C. Alessio, Un commento in volgare al «Bononienatus» di Giovanni di Bonandrea, in Lucidissima dictandi peritia. Studi di grammatica e retorica medievale, a cura di F. Bognini, Venezia 2015, pp. 375-395.

S. Ammirato, Dell'istorie fiorentine di Scipione Ammirato, Libri venti, dal principio della città infino all'anno MCCCCXXXIIII, Firenze MDC.

G. Andenna, Enrico VII e il suo progetto politico per le "tre valli del Capitolo di Milano" e per il "Regnum Italiae", in Linea Ticino. Sull'unità culturale delle genti del fiume nel Medioevo, Bellinzona 2002, pp. 29-59.

G. Andenna, Henri VII et son projet politque pour le Regnum Italiae, in Le rêve italien de la maison de Luxembourg aux XIVe et au XVe siècles, a cura di P. Margue, V. Colling-Kerg, Luxembourg, 1998², pp. 43-48.

L. Andreoli, R. Tagliani, Bibliografia unificata degli scritti di Francesco Novati, in «Carte Romanze», 4/1 (2016), pp. 279-389. 
A. Antonelli, La riflessione sul volgare a Bologna nel Duecento, in La poesia in Italia prima di Dante, a cura di F. Suitner, Ravenna 2017, pp. 171-186.

A. Antonelli, «Tanto crebbe la baldanza de' neri, che si composono col marchese di Ferrara di tòrre Bologna». La dimensione archivistica e della tradizione nella ricerca storica: logica della documentazione, esegesi delle fonti e sistema documentario comunale, in "Culture del testo e del documento», 59 (2019), pp. 21-82.

R. Antonelli, La morte di Beatrice e la struttura della storia, in Beatrice nell'opera di Dante e nella memoria europea (1290-1990), Firenze 1994, pp. 34-56.

R. Antonelli, Oscurità e piacere, in Obscuritas. Retorica e poetica dell'oscuro. Atti del XXVIII convegno interuniversitario di Bressanone (12-5 luglio 2001), a cura di G. Lachin, F. Zambon, Trento 2004, pp. 47-58.

R. Antonelli, "Subsistant igitur ignorantiae sectatores", in Guittone d'Arezzo nel settimo centenario della morte, a cura di M. Picone, Firenze 1995, pp. 337-349.

L. Armstrong, The Idea of a Moral Economy: Gerard of Siena on Usury, Restitution, and Prescription, ed. and trans. by L. Armstrong, Toronto 2016.

G. Arnaldi, Dino Compagni cronista e militante "popolano", in «La cultura», 21 (1983), pp. 37-82.

G. Arnaldi, La maledizione del sangue e la virtù delle stelle. Angioini e Capetingi nella "Commedia" di Dante, «La Cultura», 30 (1992), pp. 47-74; 185-216.

Dall'“ars dictaminis" al Preumanesimo? Per un profilo letterario del XIII secolo, a cura di F. Delle Donne, F. Santi, Firenze 2013.

E. Artifoni, Prudenza del consigliare. L'educazione del cittadino nel Liber consolationis et consilii di Albertano da Brescia (1246), in Consilium. Teorie e pratiche del consigliare nella cultura medievale, a cura di C. Casagrande, C. Crisciani, S. Vecchio, Firenze 2004, pp. 195216.

E. Artifoni, "Sapientia Salomonis". Une forme de présentation de savoir rhétorique chez les "Dictatores" italiens (première moitié du XIII e siècle), in La parole du prédicateur: $V^{e}-X V^{e}$ siècles, éds. R. M. Dessì, M. Lauwers, Nice 1997, pp. 291-310.

A. R. Ascoli, Dante and the Making of a Modern Author, Cambridge 2008.

E. Auerbach, Literary Language and its Public in Latin Antiquity and in the Middle Ages, trans. R. Manheim, Princeton 1993.

J. L. Austin, How to do things with words, ed. by J. O. Urmson, M. Sbisà, Oxford $1975^{2}$.

Autografie dell'età minore. Lettere di tre dinastie italiane tra Quattrocento e Cinquecento, a cura di M. Ferrari, I. Lazzarini, F. Piseri, Roma 2016.

L. Azzetta, Ancora sul Dante di Giovanni Villani, Andrea Lancia e la prima circolazione fiorentina della Commedia, in «Rivista di Studi Danteschi», 19 (2019), pp. 148-67.

L. Azzetta, Le "Esposizioni" e la tradizione esegetica trecentesca, in Boccaccio editore e interprete di Dante, a cura di L. Azzetta, A. Mazzucchi, Roma 2014, pp. 275-292.

R. Badalì, I codici romani di Lucano (III), in «Bollettino del Comitato per la preparazione dell'edizione nazionale dei classici greci e latini», n.s. 23 (1975), pp. 15-85.

F. Baethgen, Dante und Petrus de Vinea, in «Sitzungsberichte der Bayerischen Akademie der Wissenschaften. Phil.-hist. Kl», 1955, Heft 3, pp. 413-441.

F. Baethgen, Der Anspruch des Papsttums auf das Reichsvikariat: Untersuchungen zur Theorie und Praxis der potestas indirecta in temporalibus, in «Zeitschrift der SavignyStiftung für Rechtsgeschichte: Kanonistische Abteilung», 10 (1920), pp. 168-268.

L. Baggioni, La forteresse de la raison. Lectures de l'humanisme politique florentin, d'après l'œuvre de Coluccio Salutati, Genève 2015. 
M. Baglio, Filippo Villani, in Autografi dei letterati italiani. Le origini e il Trecento. 1, a cura di G. Brunetti, M. Fiorilla, M. Petoletti, Roma 2013.

C. Balbo, Vita di Dante, Torino 1840.

S. U. Baldassarri, La Invectiva in florentinos di Antonio Loschi, in «Esperienze Letterarie», 35/1 (2010), pp. 3-28.

S. U. Baldassarri, La vipera e il giglio. Lo scontro tra Milano e Firenze nelle invettive di Antonio Loschi e Coluccio Salutati, Roma 2012.

S. U. Baldassarri, Prime ricerche per un'edizione critica della "Invectiva Antonium Luscum", in «Medioevo e Rinascimento», 19 (2008), pp. 105-130.

Z. Barański, «Chiosar con altro testo». Leggere Dante nel Trecento, Fiesole 2001.

Z. Barański, «E Cominciare stormo»: Notes on Dante's Sieges, in «Legato con amore in un volume». Essays in Honour of John A. Scott, eds. J. J. Kinder, D. Glenn, Firenze 2013, pp. 175-204.

T. Barbavara di Gravellona, Insegne araldiche sul monumento di Antonio d'Orso, vescovo fiorentino, in «Emblemata», 5 (1999) pp. 153-172.

A. Barbero, Il mito angioino nella cultura italiana e provenzale fra Duecento e Trecento, Torino 1983.

A. Barbero, L'ttalia comunale e le dominazioni angioine, in I comuni di Jean-Claude Maire Vigueur. Percorsi storiografici, a cura di M. T. Caciorgna, S. Carocci, A. Zorzi, Roma 2014, pp. 9-32.

M. Barbi, Nuovi problemi della critica dantesca. VII. L'Italia nell'ideale politico di Dante, in «Studi Danteschi», XXIV (1939), pp. 5-37.

M. Barbi, Per un passo dell'epistola all'amico fiorentino e per la parentela di Dante, in "Studi danteschi», 2 (1920), pp. 115-148, poi in M. Barbi, Problemi di critica dantesca. Seconda serie (1920-1937), Firenze 1941, pp. 305-328.

M. Barbi, Problemi di critica dantesca. Prima serie (1893-1918), Firenze 1934.

M. Barbi, rec. a Scartazzini, Dantologia, in «Bullettino della Società Dantesca Italiana», n.s. 2 (1894-1895), pp. 2-24.

M. Barbi, Sulla dimora di Dante a Forli, in «Bullettino della Società Dantesca Italiana», n.s. VIII (1892), pp. 21-28, poi in Barbi Problemi di critica dantesca. Prima serie (18931918), Firenze 1934, pp. 189-195.

J. Barnes, Moroello "vapor": metafora meteorica e visione dantesca del marchese di Giovagallo, in «Dante Studies», 124 (2006), pp. 35-56.

T. Baron, La conoscenza della "Commedia" prima del 1315, Ferrara 1965.

E. Bartoli, I conti Guidi nelle raccolte inedite di modelli epistolari del XII secolo, Spoleto 2015.

M. Bartoli, La Caduta di Gerusalemme. Il commento al Libro delle Lamentazioni di Pietro di Giovanni Olivi, Roma 1991.

J. Bartuschat, Le biografie di Dante tra dati documentali e costruzione retorica, in Dante fra il settecentocinquantenario della nascita (2015) e il settecentenario della morte (2021), a cura di E. Malato, A. Mazzucchi, Roma 2016, 1, pp. 171-198.

A. Barzazi, Mittarelli, Giovanni Benedetto, in DBI, 75 (2011).

F. Bausi, Coluccio traduttore, in «Medioevo e Rinascimento», 22 (2008), pp. 33-58.

F. Beggiato, Giovanni di Garlandia, in ED, 3.

A. Bellieni, Tra Petrarca e Salutati: i carmi e le epistole di Francesco da Fiano, tesi di dottorato, rel. V. Fera, Università degli Studi di Messina 2014.

P. Bellini, «Dominus Totius mundi»: L'imperatore dei romani e i popoli estranei al popolo romano (sec. XII-XIV), in Popoli e spazio romano tra diritto e profezia, Napoli 1986, pp. 247-271. 
S. Bellomo, Dizionario dei commentatori danteschi. L'esegesi della Commedia da lacopo Alighieri a Nidobeato, Firenze 2004.

S. Bellomo, Il sorriso di llaro e la prima redazione in latino della "Commedia", in "Studi sul Boccaccio», 32 (2004), pp. 201-235.

S. Bellomo, L'interpretazione di Dante nel Tre e nel Quattrocento in Storia della letteratura italiana, vol. XI. La critica letteraria dal Due al Novecento, a cura di E. Malato, P. Orvieto, pp. 131-159.

M. Bertè, M. Fiorilla, Il Trattatello in laude di Dante, in Boccaccio editore e interprete di Dante, a cura di L. Azzetta, A. Mazzucchi, Roma 2014, pp. 41-72.

S. Bertelli, M. Cursi, Boccaccio copista di Dante, in Boccaccio editore e interprete di Dante, Atti del Convegno internazionale di Roma 28-30 ottobre 2013, a cura di L. Azzetta, A. Mazzucchi, Roma 2014, pp. 73-112.

E. Bertin, La pace di Castelnuovo Magra (6 ottobre 1306). Otto argomenti per la paternità dantesca, in «Italia medioevale e umanistica», 46 (2005), pp. 1-34.

L. Bertolini, I volgarizzamenti italiani degli apocrifi (secc. XIII-XV): un sondaggio, in Seneca. Una vicenda testuale. Catalogo della Mostra di manoscritti ed edizioni, Firenze, Biblioteca Medicea Laurenziana, 2 aprile-2 luglio 2004, a cura di T. De Robertis, G. Resta, Firenze 2004, pp. 357-364.

D. Birnbaum Dante's Briefe, in «Blätter für literarische Unterhaltung», 341/7 (1843), pp. 1370-1372.

M. Berté, M. Petoletti, La filologia medievale e umanistica, Bologna 2017.

V. Biagi, Dante e il cardinal Niccolò da Prato, in Dante e Prato: conferenze tenute nel salone della R. Accademia dei Misoduli in Prato («Archivio storico pratese», Suppl. I), Prato 1922, pp. 75-98.

V. Bianchi, La poesia d'amore nelle corti del Trecento: Cino da Pistoia, Dante e Moroello Malaspina, in «Archivio Storico per le Province Parmensi», 25 (1973), pp. 31-56.

Bibliothecae Apostolicae Vaticanae codices manu scripti recensiti. Codices Vaticani latini, recensuit B. Nogara, Romae 1912, vol. III. Codices 1461-2059.

M. Bicchierai, Guidi, Aghinolfo, in DBI 61 (2004).

M. Bicchierai, Guidi, Guido, in DBI 61 (2004).

M. Bicchierai, Guidi, Guido Novello (il Giovane o di Reggiolo), in DBI 61 (2004).

M. Bicchierai, Guidi, Guido Salvatico, in DBI 61 (2004).

M. Bicchierai, Guidi, Ildebrandino, in DBI 61 (2004).

M. Bicchierai, Guidi, Manfredi, in DBI 61 (2004).

M. Bicchierai, Guidi, Tegrimo, in DBI 61 (2004).

G. Billanovich, Giovanni del Virgilio, Pietro da Moglio, Francesco da Fiano, in «Italia medioevale e umanistica», 6 (1963), pp. 203-34, e 7 (1964), pp. 279-324.

G. Billanovich, La leggenda dantesca del Boccaccio. Dalla lettera di llario al "Trattatello in laude di Dante", in «Studi danteschi», 28 (1949), pp. 45-144.

G. Billanovich, L'altro stil nuovo. Da Dante teologo a Petrarca filologo, in «Studi petrarcheschi», 11 (1994), pp. 1-98.

G. Billanovich, Petrarca letterato, I. Lo scrittoio del Petrarca, Roma 1947.

G. Billanovich, Petrarca, Pietro da Moglio e Pietro da Parma, in «Italia medioevale e umanistica», 22 (1979), pp. 367-395.

G. Billanovich, Restauri boccacceschi, Roma 1947.

G. Billanovich, Tra Dante e Petrarca, in «Italia medioevale e umanistica», 8 (1965), pp. 1-44.

D. Bloch, La formation de la Bibliothèque du Roi, in Histoire des bibliothèques françaises, sous la direction d'A. Vernet, Paris 1989, vol. I. Les bibliothèques médiévales. Du VIe siècle à 1530 , pp. 311-331. 
M. W. Bloomfield, B. G. Guyot et al., Incipits of Latin Works on the Virtues and Vices, 11001500 A. D. Including a Section of Incipits of Works on the Pater Noster, Cambridge (Massachusetts) 1979.

A. Boccia, Forme della creazione letteraria nell'epistolario di Pier della Vigna, in Dall'“ars dictaminis" all'umanesimo? Per un profilo letterario del secolo XIII, a cura di F. Delle Donne, F. Santi, Firenze 2013, pp. 83-100.

A. Boccia, La redazione maggiore dell'epistolario di Pier della Vigna. Rapporti tra i testimoni e prospettive editoriali, in «ArNoS. Archivio normanno-svevo. Studi sul mondo euromediterraneo dei secoli XI-XIII», 1 (2008), pp. 151-160.

F. Bock, Kaisertum, Kurie und Nationalstaat zu Beginn des 14. Jahrhunderts, in «Römische Quartalschrift», 44 (1936), pp. 105-122; 169-220.

F. Bock, Studien zum politischen Inquisitionsprozess Johanns XXII., in «Quellen und Forschungen aus italienischen Archiven und Bibliotheken», 26 (1935/1936), pp. 21-142.

G. P. Bognetti, Note per la storia del passaporto e del salvacondotto (a proposito di documenti genovesi del Sec. XII), Pavia 1933.

F. Bognini, F. Delle Donne, Partes, in "Ars dictaminis". Handbuch der mittelalterlichen Briefstillehre, a cura di F. Harthmann, B. Grévin, Stuttgart 2019, in corso di stampa.

B. Bombi, The 'Babylonian captivity' of Petracco di ser Parenzo dell'Incisa, father of Francesco Petrarca, in «Historical Research», 83-221 (2010), pp. 431-443.

K. Borchardt, Petrus de Vinea und die nach ihm benannten Mustersammlungen, in «Deutsches Archiv für Erforschung des Mittelalters», 70 (2014), pp. 541-594.

P. Borsa, «Scuro saccio che par lo / meo detto» (I Know that my Word Seems Obscure): Wordplay and Obscurity in Thirteenth-Century Italian Poetry, in Etymology and Wordplay in Medieval Literature, ed. M. Males, Turnhout 2018, pp. 137-168.

D. Bortoluzzi, I rapporti diplomatici tra le città italiane alla fine del Duecento: il caso di Bologna e Firenze, in Dante attraverso i documenti. II. Presupposti e contesti dell'impegno politico a Firenze (1295-1302), a cura di G. Milani, A. Montefusco, in «Reti medievali», 18/1 (2017), pp. 493-510.

M. Boschi Rotiroti, Un Seneca copiato in Umbria. Firenze, Biblioteca Medicea Laurenziana, Conv. Soppr. 533, in Seneca. Una vicenda testuale. Catalogo della Mostra di manoscritti ed edizioni, Firenze, Biblioteca Medicea Laurenziana, 2 aprile-2 luglio 2004, a cura di T. De Robertis, G. Resta, Firenze 2004, p. 156 n. 21.

J. P. Boyer, Conclusions. Définir une haute administration au Moyen Âge tardif, in Les grands officiers dans les territoires angevins I grandi ufficiali nei territori angioini, a cura di R. Rao, Roma 2016.

J. P. Boyer, Florence et l'idée monarchique. La prédication de Remigio dei Girolami sur les Angevins de Naples, in La Toscane et les Toscans autour de la Renaissance. Cadres de vie, société, croyances. Mélanges offerts à Charles-M. de La Roncière, Aix-en-Provence 1999, pp. 363-376.

J. P. Boyer, Le droit civil entre studium et cour de Naples. Barthélemy de Capoue et son cercle, in La justice temporelle dans les territoires angevins, Roma 2005.

J. P. Boyer, Le fisc d'après les juristes napolitains (fin XIII ${ }^{e}$-début XIVe siècle), in Périphéries financières.

J. P. Boyer, Roberto d'Angiò, re di Sicilia-Napoli, in DBI, 87 (2017).

W. Bowsky, Clement $V$ and the Emperor-elect, in «Medievalia et Humanistica», 12 (1958), pp. 52-69.

W. Bowsky, Florence and Henry de Luxembourg, King of Romans: The Rebirth of Guelfism, in «Speculum», 33 (1958), pp. 177-203. 
W. Bowsky, Henry VII in Italy. The Conflict between Empire and City-States, Lincoln (Nebraska) 1960.

S. Brambilla, Zanobi da Strada volgarizzatore di Cicerone: edizione critica del "Sogno di Scipione», in «Studi petrarcheschi», n.s. 13 (2000), pp. 1-79.

V. Branca, Tradizione delle opere di Giovanni Boccaccio. I. Un primo elenco dei codici e tre studi, Roma 1958.

V. Branca, Tradizione delle opere di Giovanni Boccaccio. II. Un secondo elenco di manoscritti e studi sul testo del "Decameron" con due appendici, Roma 1991.

V. Branca, Un quarto elenco di codici, in «Studi sul Boccaccio», 9 (1975-1976), pp. 1-19.

V. Branca, Un sogno, in Ponte Santa Trinita. Per amore di libertà, per amore di verità, Venezia 1987, pp. 197-199.

F. Brancucci, Italia. Storia, in Enciclopedia Dantesca, Roma 1970-1978.

H. Bresslau, Manuale di diplomatica per la Germania e l'Italia, trad. di A. M. Voci-Roth, Roma 1998.

Dante and Biography, a cura di E. Brilli, in «Dante Studies», 136 (2019), pp. 133-231.

E. Brilli, Firenze 1300-1301. Le cronache antiche (XIV secolo in.), in «Reti Medievali Rivista», 17/2 (2016), pp. 113-151.

E. Brilli, Firenze e il profeta. Dante fra teologia e politica, Roma 2012.

E. Brilli, Profeti, veri e falsi, e "quasi profeti". Il profetismo (non solo dantesco) secondo Giovanni Villani, in Dante poeta cristiano e la cultura religiosa medievale. In ricordo di Anna Maria Chiavacci Leonardi, a cura di G. Ledda, Ravenna 2018, pp. 167-198.

E. Brilli, Reminiscenze scritturali (e non) nelle epistole politiche dantesche, in "La Cultura», 45/3 (2007), pp. 439-455.

E. Brilli, The Interplay between Political and Prophetic Discourse: a Reflection on Dante's Autorship in Epistles V-VII, in Brilli, Fenelli, Wolf, Images and Words in Exile, pp. 153-169.

E. Brilli, L. Fenelli, G. Wolf (a cura di), Images and Words in Exile. Avignon and Italy during the first half of the fourteenth century, Firenze 2015.

E. Brilli, A. Fontes Baratto, A. Montefusco, Sedurre l'imperatore. La lettera di Francesco da Barberino a Enrico VII a nome della corona romana (1311), in «Italia medioevale e umanistica», 57 (2016), pp. 37-89.

T. Broser, Les règles de l'ars dictaminis à la Curie pontificale durant le XIIIe siècle, in Le dictamen dans tout ses états. Perspectives de recherche sur la théorie et la pratique de l'ars dictaminis, éds. B. Grévin, A.-M. Turcan-Verkerk, Turnhout 2015, pp. 243-256.

G. Brugnoli, Il latino di Dante, in Dante e Roma, Atti del Convegno di studi a cura della «Casa di Dante», Roma, 8-9-10 aprile 1965, Firenze 1965, pp. 51-71.

G. Brugnoli, L'invidia di Pier della Vigna, in «Critica del testo», 5 (2002), pp. 641-652.

G. Brugnoli, Sarno, in ED, 5.

G. Brugnoli, Studi Danteschi. 1. Per suo richiamo, Pisa 1998.

F. Bruni, Italia. Vita e avventura di un'idea, Bologna 2010.

F. Bruni, La città divisa. Le parti e il bene comune da Dante a Guicciardini, Bologna 2003.

F. Bruni, Dialogi ad Petrum Paulum Histrum, a cura di S. U. Baldassarri, Firenze 1994.

W. W. Buckland, A. McNair, Roman Law and Common Law, Cambridge 1952.

M. Buonocore, Recensio Horatianorum codicum qui in Bibliotheca Apostolica Vaticana asservantur, in «Giornale italiano di Filologia», 45 (1993), pp. 3-28.

K. Burdach, Von Mittelalter zur Reformation. Forschungen zur Geschichte der deutschen Bildung, Berlin 1912.

D. Burr, Olivi on Prophecy, in «Cristianesimo nella storia», 17 (1996), pp. 369-91. 
A. M. Cabrini, Le Historiae del Bruni: risultati e ipotesi di una ricerca sulle fonti, in Leonardo Bruni, cancelliere della Repubblica di Firenze, a cura di P. Viti, Firenze 1990, pp. 247-319.

A. Cadili, La diplomazia e le missioni legatizie, in «Memorie domenicane», n.s. 44 (2013), Niccolò da Prato e i frati Predicatori tra Roma ed Avignone, a cura di M. Benedetti, L. Cinelli, pp. 85-139.

R. Caggese, Roberto d'Angiò e i suoi tempi, Firenze 1922-1930.

G. M. Cagni, I codici Vaticani Palatino-Latini appartenuti alla biblioteca di Giannozzo Manetti, in «La Bibliofilia», 62 (1960), pp. 1-43.

G. Caiti-Russo, Il marchese Moroello Malaspina testimone ideale di un dibattito tra Dante e Cino sull'eredità trobadorica, in «Dante Studies», 124 (2006), pp. 137-148.

G. Caiti-Russo, Les Troubadours et la cour des Malaspina, Montpellier 2005.

F. Calasso, I glossatori e la teoria della sovranità, Firenze 1945.

M. Camargo, The Libellus de arte dictandi rhetorice attributed to Peter of Blois, in «Speculum», 59 (1984), pp. 16-41.

A. Campana, Calvi, Pellegrino, in ED, 1.

K. M. Camper, The stylistic virtues of clarity and obscurity in Augustine of Hippo's De doctrina christiana, in «Advances in the History of Rhetoric», 16/1 (2013), pp. 58-81.

F. Canaccini, Ghibellini e Ghibellinismo in Toscana da Montaperti a Campaldino, Roma 2010.

J. Canning, The Political Thought of Baldus de Ubaldis, Cambridge-New York 1987.

C. Cantù, Schiarimenti e note alla storia universale, Torino 1842.

0. Capitani, Cupidigia, avarizia, bonum commune in Dante Alighieri e in Remigio de' Girolami, in Da Dante a Bonifacio VIII, Roma 2007, pp. 95-111.

0. Capitani, La storiografia medievale, in La storia. I grandi problemi dal medioevo all'età contemporanea, a cura di N. Tranfaglia, M. Firpo, Torino 1988, I/1 /l medioevo. I quadri generali, pp. 757-92.

O. Capitani, Remigio de' Girolami, in Enciclopedia Dantesca, Roma 1970-1978.

L. Capo, La cronachistica italiana dell'età di Federico II, in «Rivista storica italiana», 114 (2002), pp. 380-430.

F. Cardini, Cerchi, Giovanni, in DBI, 23 (1979).

F. Cardini, La Romfahrt di Enrico VII, in Il viaggio di Enrico VII in Italia, a cura di M. Tosti Croce, Città di Castello 1993, pp. 1-11.

G. Carletti, Dante politico: la felicità terrena secondo il pontefice, il filosofo, l'imperatore, Pescara 2006.

N. L. Carlotto, Pietro «Nan» da Marano: ritratto di un cortigiano scaligero, in Gli Scaligeri 1277-1387. Saggi e schede raccolti in occasione della mostra storico-documentaria, a cura di G. M. Varanini, Verona 1988, pp. 143-148.

U. Carpi, La nobiltà di Dante, Firenze 2004.

U. Carpi, L'Inferno dei guelfi e i principi del Purgatorio, Milano 2013.

U. Carpi, Un congedo da Firenze?, in L'inferno dei guelfi e i principi del Purgatorio, Milano 2013, pp. 91-98.

U. Carpi, Un inferno guelfo, in L'inferno dei guelfi ei principi del Purgatorio, Milano 2013, pp. 101-167.

S. Carrai, Guittone e le origini dell'epistolografia in volgare, in «Giornale storico della letteratura italiana», 192 (2015), pp. 161-171.

D. Carron, Remigio de' Girolami dans la Florence de Dante, in «Reti Medievali. Rivista», 18 (2017) (consultato online <http://www.rmojs.unina.it/index.php/rm/article/view/5150>).

A. Casadei, Dante oltre la Commedia, Bologna 2013.

C. Casagrande, S. Vecchio, I sette vizi capitali. Storia dei peccati nel Medioevo, Torino 2000. 
U. Cassuto, I manoscritti Palatini ebraici della Biblioteca Apostolica Vaticana e la loro storia, Città del Vaticano 1935.

J. Catto, Ideas and Experience in the Political Thought of the Aquinas, in «Past and Present», 71 (1976), pp. 3-21.

A. Cavalcabò, Un Cremonese Consigliere Ducale di Milano, in «Bollettino Storico Cremonese», 2 (1932), pp. 5-56.

G. Cavallo, Dal segno incompiuto al segno negato, in Alfabetismo e cultura scritta, a cura di A. Bartoli Langeli e A. Petrucci, in «Quaderni storici», XIII (1978), n. 38, pp. 466-487.

M. L. Ceccarelli Lemut, Ghibellini e guelfi bianchi alla corte pisana dell'imperatore, in Enrico VII, Dante e Pisa a settecento anni dalla morte dell'imperatore e della monarchia (13132013), a cura di G. Petralia, M. Santagata, Ravenna 2016, pp. 93-109.

I. Ceccherini, Mercanti copisti delle opere di Dante, in Intorno a Dante. Ambienti culturali, fermenti politici, libri e lettori nel XIV secolo, a cura di L. Azzetta, A. Mazzucchi, Roma 2018, pp. 295-306.

E. Cecchini, Sul testo dell'epistola di Dante Cardinalibus Ytalicis, in Dicti studiosus. Scritti di filologia offerti a Scevola Mariotti dai suoi allievi, Urbino 1990, pp. 387-406.

A. Cecilia, Italia, in Enciclopedia Dantesca, Roma 1970-1978.

R. Cella, Il "Centiloquio" di Antonio Pucci e la "Nuova Cronica" di Giovanni Villani, in Firenze alla vigilia del Rinascimento: Antonio Pucci e i suoi contemporanei: atti del convegno di Montreal (22-23 ottobre 2004), a cura di M. Bendinelli Predelli, Fiesole 2006, pp. 84-110.

F. Cengarle, Enrico VII e le città lombarde (1311), tra duttilità politica e affermazioni autoritarie: qualche nota, in Enrico VII e il governo delle città italiane (1310-1313), a cura di G. M. Varanini, in «Reti Medievali», 15 (2014), 1: https://doi.org/10.6092/15932214/417.

F. Cheneval, Die Rezeption der Monarchia Dantes bis zur Editio Princeps im Jahre 1559. Metamorphosen eines philosophischen Werkes, München 1995.

G. Cherubini, Dante e le attività economiche del tempo suo, in Scritti toscani. L'urbanesimo medievale e la mezzadria, Firenze 1991, pp. 313-325.

G. Cherubini, Gargonza, in ED, 3.

G. Cherubini, L'immagine di Federico II nella cultura toscana del Trecento, in Scritti toscani. L'urbanesimo medievale e la mezzadria, Firenze 1991, pp. 289-311.

G. Cherubini, San Godenzo, in ED, 5.

J. Chesley Mathews, Richard Henry Wilde's Knowledge of Dante, in «Italica», 45/1 (1968), pp. 28-46.

F. Chiappelli, Osservazioni sulle tre epistole dantesche a Margherita imperatrice, in «Giornale storico della letteratura italiana», 140 (1963), pp. 558-565.

L. Chiappelli, Cino da Pistoia giurista, Pistoia 1999.

P. Chiesa, L'impiego del "cursus" in sede di critica testuale: una prospettiva diagnostica, in Meminisse iuvat. Studi in memoria di Violetta de Angelis, a cura di F. Bognini, Pisa 2012, pp. 279-304.

S. A. Chimenz, Alighieri Dante, in DBI, 2 (1961).

$\mathrm{S}$. Ciampi, Monumenti di un manoscritto autografo e lettere inedite di messer Giovanni Boccaccio, il tutto nuovamente trovato e illustrato da S. Ciampi, seconda edizione dal medesimo rivista e accresciuta, Milano 1830.

G. Ciappelli, Introduzione, in Famiglia, memoria, identità tra Italia ed Europa nell'età moderna. Atti del convegno internazionale (Trento, 4-5 ottobre 2007), a cura di G. Ciappelli, Bologna 2009, pp. 11-36. 
A. Ciaralli, Tra segno e disegno. La scrittura dell'italiano e i suoi designer, in L'italiano e la creatività: marchi e costumi, moda e design, a cura di P. D’Achille, G. Patota, Firenze 2016, pp. 117-131.

Ciolo, in ED, 2.

C. Cipolla, F. Cipolla, Antiche cronache veronesi, Venezia 1890.

S. Cohn, The manuscript evidence for the letters of Peter of Blois, in «English Historical Review», 41 (1926), pp. 43-60.

F. Cognasso, Arrigo VII, Milano 1973.

F. Cognasso, L'unificazione della Lombardia sotto Milano, in Storia di Milano V. La signoria dei Visconti (1310-1392), Milano 1955, pp. 1-567.

F. Colagrosso, Gli uomini di corte nella "Divina Commedia", in «Studi di letteratura italiana», 2 (1900), pp. 24-57.

P. Colomb de Batines, Bibliografia dantesca, ossia catalogo delle edizioni, traduzioni, codici ..., Prato 1845.

M. Conetti, L'origine del potere legittimo: spunti polemici contro la donazione di Costantino da Graziano a Lorenzo Valla, Parma 2004.

D. Consoli, Alto, in ED, 1.

G. Constable, Letters and letter collection, Turnhout 1976.

E. Conte, "Vetustas". Prescrizione acquisitive e possesso dei diritti nel Medioevo, in Uso, Tempo, Possesso dei Diritti. Una ricerca storica e di diritto positivo, Torino 1999, pp. 49-128.

B. Corio, Storia di Milano, a cura di A. Morisi Guerra, I, Torino 1978.

La corrispondenza epistolare in Italia, 2: Forme, stili e funzioni della scrittura epistolare nelle cancellerie italiane. Atti del Convegno di studio (Roma, 20-21 giugno 2011), a cura di P. Cammarosano, S. Gioanni, Trieste 2013.

E. Cortese, La norma giuridica: Spunti teorici nel diritto comune classico, Milano 1964.

E. Cortese, Scritti, a cura di I. Birocchi, U. Petronio, Spoleto 1999.

M. Corti, Dante a un nuovo crocevia, Firenze 1981.

S. Cristaldi, La profezia imperfetta. Il Veltro e l'escatologia medievale, Caltanissetta-Roma 2011.

E. Cristiani, I fuorusciti toscani di parte "bianca" tra il sec. XIII e XIV, in Exil et civilisation en Italie (XII ${ }^{e} X V I^{e}$ siècles), éds. J. Heers, C. Bec, Nancy 1990, pp. 61-66.

G. Cura Curà, Cultura classica e biblica nella prospettiva politica dell'epistola dantesca a Enrico VII, in «La Parola del testo», 14/2 (2010), pp. 269-332.

M. Cursi, Percezione dell'autografia e tradizione dell'autore, in «Di mano propria». Gli autografi dei letterati italiani. Atti del convegno internazionale di Forlì, 24-27 novembre 2008, a cura di G. Baldassarri, M. Motolese, P. Procaccioli, E. Russo, Roma 2010, pp. 159-184.

A. D’Addario, Uberti, Lapo degli, in Enciclopedia Dantesca, Roma 1970-1978.

A. Dalzell, The "Forma dictandi" attributed to Albert of Morra and related texts, in «Mediaeval Studies», 39 (1977), pp. 440-465.

E. D’Angelo, Le sillogi epistolari tra "autori" $e$ "compilatori". Il caso di Pietro di Blois, in Dall'“ars dictaminis" al preumanesimo? Per un profilo letterario del secolo XIII, a cura di F. Delle Donne, F. Santi, Firenze 2013, pp. 25-42.

E. D’Angelo, J. M. Ziolkowski (eds.), Auctor et Auctoritas in Latinis Medii Aevi litteris. Author and Authorship in Medieval Latin literature. Proceedings of the 6th Congress of the International Medieval Latin Committee, Firenze 2014.

Dante attraverso i documenti. I. Famiglia e patrimonio (secolo XII-1300 circa), a cura di G. Milani, A. Montefusco, in «Reti Medievali Rivista», 15/2 (2014), https://doi.org/ 10.6092/1593-2214/436. 
Dante attraverso i documenti. II. Presupposti e contesti dell'impegno politico a Firenze (12951302), a cura di G. Milani, A. Montefusco, in «Reti medievali», 18/1 (2017), https:// doi.org/10.6092/1593-2214/5154.

R. Davidsohn, Dante, i Guidi e gli Elisei, in «Bullettino della società dantesca», n.s. XIX (1912), pp. 221-225.

R. Davidsohn, Forschungen zur älteren Geschichte von Florenz, I-IV, Berlin 1896-1908.

R. Davidsohn, Geschichte von Florenz III: die letzten Kämpfe gegen die Reichsgewalt, Berlin 1912 (tr. it. Storia di Firenze, I-VI, Firenze 1956-68).

C. T. Davis, Dante and the Empire, in Dante and the idea of Rome, Oxford 1957, pp. 139-194.

C. T. Davis, L'Italia di Dante, Bologna 1984.

C. T. Davis, Remigio de' Girolami and Dante. A Comparison of their Conceptions of Peace, in «Studi Danteschi», 16 (1959), pp. 123-136.

A. De Angelis, Il concetto d'imperium e la comunità soprannazionale in Dante, Milano 1965.

V. de Angelis, Magna questio preposita coram Dante et domino Francisco Petrarca et Virgiliano, in "Studi petrarcheschi», n.s. 1 (1984), pp. 103-209.

V. de Angelis, Un percorso esemplare della lezione sui classici nel Trecento: Giovanni del Virgilio e l'“Achilleide" di Stazio, in I classici e l'Università umanistica. Atti del Convegno di Pavia, 22-24 novembre 2001, a cura di L. Gargan, M. P. Mussini Sacchi, Messina 2006, pp. 225-260.

A. C. de la Mare, The Handwriting of Italian Humanists, Oxford 1973, vol. I. Francesco Petrarca, Giovanni Boccaccio [et al.].

H. Decker-Hauff, Graf Berthold von Neuffen: Graf von Marstetten und Graisbach, Kaiserlicher Generalvikar für Italien, in Schwäbische Lebensbilder VI, hsgb. von H. Haering, M. Miller, R. Uhland, Stuttgart 1957, pp. 28-39.

C. De Dominicis, Membri del Senato della Roma pontificia. Senatori, Conservatori, Caporioni e loro Priori e Lista d'Oro delle famiglie dirigenti (secc. X-XIX), Roma 2009.

C. Delcorno, "Ma noi siam peregrin come voi siete". Aspetti penitenziali del "Purgatorio", in Da Dante a Montale. Studi di filologia e critica letteraria in onore di Emilio Pasquini, a cura di G. M. Anselmi et al., Bologna 2005, pp. 11-30.

A. Della Torre, L'epistola all'“amico fiorentino”, in «Bullettino della Società dantesca italiana», n.s. 12 (1905), pp. 121-174.

F. Delle Donne, Autori, redazioni, trasmissioni, ricezione. I problemi editoriali delle raccolte di Dictamina di epoca sveva e dell'epistolario di Pier della Vigna, in «ArNoS. Archivio normanno-svevo», 2 (2009), pp. 7-28.

F. Delle Donne, Die Briefsammlung des Petrus des Vinea und die Probleme der Überlieferung von Dictamina in der Zeit Friedrichs II., in Kuriale Briefkultur im späteren Mittelalter. Gestaltung - Überlieferung - Rezeption, a cura di T. Broser, A. Fischer, M. Thumser, Köln - Weimar - Wien 2015, pp. 223-233.

F. Delle Donne, Federico II, Pier della Vigna, la propaganda cancelleresca e i modelli retorici, in L'epistolario di Pier della Vigna, coordinamento di E. D’Angelo, Soveria Mannelli 2014, pp. 51-76.

F. Delle Donne, La cultura e gli insegnamenti retorici nell'Alta Terra di Lavoro, in Suavis terra, inexpugnabile castrum. L'Alta Terra di Lavoro dal dominio svevo alla conquista angioina, Arce 2007, pp. 133-57.

F. Delle Donne, La dedica del cosiddetto 'Opus metricum' di lacopo Stefaneschi, in «Filologia mediolatina. Studies in Medieval Latin Texts and their Transmission», 17 (2010), pp. 85104.

F. Delle Donne, La porta del sapere. Cultura alla corte di Federico II, Roma 2019. 
F. Delle Donne, Le formule di saluto nella pratica epistolare medievale. La 'Summa salutationum' di Milano e Parigi, in «Filologia Mediolatina», 9 (2002), pp. 251-279.

F. Delle Donne, Le lettere di Pier della Vigna: da Epistolae a dictamina, da "insegne del potere" a "emblemi retorici", in La corrispondenza epistolare in Italia 2. Forme, stili e funzioni della scrittura epistolare nelle cancellerie italiane (secoli $V-X V$ ) / Les correspondances en Italie 2. Formes, styles et fonctions de l'écriture épistolaire dans les chancelleries italiennes ( $V^{e}-X V^{e}$ siècle). Atti del convegno di studio (Roma, 20-21 giugno 2011), a cura di P. Cammarosano, S. Gioanni, Trieste-Roma 2013, pp. 239-52.

F. Delle Donne, Le parole del potere: l'epistolario di Pier della Vigna, in Pier delle Vigne in catene da Borgo San Donnino alla Lunigiana medievale: itinerario alla ricerca dell'identità storica, economica e culturale di un territorio. Atti del Convegno itinerante (28 maggio 2005-13 maggio 2006), a cura di G. Tonelli, Sarzana 2006, pp. 111-122.

F. Delle Donne, «Per scientiarum haustum et seminarium doctrinarum». Storia dello Studium di Napoli in età sveva, Bari 2010.

F. Delle Donne, Tommaso di Capua e la cancelleria papale: tra normativa retorica e comunicazione politica, in Dall'“ars dictaminis" al preumanesimo? Per un profilo letterario del XIII secolo, a cura di F. Delle Donne, F. Santi, Firenze 2013, pp. 43-61.

F. Delle Donne, Tra antico e moderno: lacopo Stefaneschi e la cultura letteraria del suo tempo, in «Rivista di cultura classica e medioevale», 62 (2020), in corso di stampa.

F. Delle Donne, Una costellazione di epistolari del XIII secolo: Tommaso di Capua, Pier della Vigna, Nicola da Rocca, in «Filologia Mediolatina», 11 (2004), pp. 143-59.

F. Delle Donne, Una fonte per l'ep. XI: Dante, Pier della Vigna e il codice Fitalia, in «Spolia. Journal of Medieval Studies», 5 (2019), c.d.s.

I. Del Lungo, Dell'esilio di Dante, Firenze 1881.

I. Del Lungo, Dino Compagni e la sua Cronica, Firenze 1879-1887.

C. Del Vento, «L'avara povertà di Catalogna» e la «milizia» di Roberto d'Angiò (Pd VIII 76148), in «Nuova Rivista di Letteratura Italiana», 1 (1998), pp. 339-372.

D. De Robertis, Censimento dei manoscritti di rime di Dante (I), in «Studi danteschi», 37 (1960), pp. 141-273.

D. De Robertis, Il caso di Cavalcanti, in Dante e la Bibbia, Atti del convegno internazionale (Firenze, 26-28 settembre 1986), a cura di G. Barblan, Firenze 1988, pp. 341-50.

R. Desmed, Le cercle des préhumanistes de Padoue et les commentaires des tragédies de Sénèque, in «Scriptorium», 25 (1971), pp. 82-84.

R. M. Dessì, I nomi dei Guelfi e Ghibellini da Carlo I d'Angiò a Petrarca, in Guelfi e Ghibellini nell'Italia del Rinascimento, a cura di M. Gentile, Roma 2004, pp. 3-78.

R. M. Dessì, "Nec predicator sum": Pétrarque orateur et la communication verbale au temps de Visconti, in Humanistes, clercs et laïcs dans l'Italie du XIII ${ }^{e}$ au début du XVI ${ }^{e}$ siècle, éds. C. Caby, R. M. Dessì, Turnhout 2012, pp. 41-119.

A. De Vincentiis, Le signorie angioine a Firenze: storiografia e prospettive, in «Reti Medievali», 2/2 (2001), <http://dx.doi.org/10.6092/1593-2214/237>.

A. De Vincentiis, Origini, memoria, identità a Firenze nel XIV secolo. La rifondazione di Carlomagno, in «Mélanges de l'École française de Rome. Moyen Âge», 115 (2003), pp. 385-443.

A. De Vincentiis, Scrittura storica e politica cittadina: la Cronaca Fiorentina di Marchionne di Coppo Stefani, in «Rivista Storica Italiana», 108 (1996), pp. 230-297.

S. Diacciati, Dante a Campaldino, in «Le tre Corone», 6 (2019), pp. 11-25.

S. Diacciati, Dante: relazioni sociali e vita pubblica, in Dante attraverso i documenti. I. Famiglia e patrimonio (secolo XII-1300 circa), a cura di G. Milani, A. Montefusco, in «Reti Medievali Rivista», 15/2 (2014), pp. 243-270. 
S. Brambilla, Per la fortuna volgare del «Somnium Scipionis»: da Zanobi da Strada alla cerchia di Giovanni delle Celle, in «Studi petrarcheschi», 11 (1994), pp. 200-238.

F. Di Capua, Appunti sul "cursus", o ritmo prosaico nelle opere latine di Dante Alighieri, Castellammare di Stabia 1919.

F. Di Capua, Fonti ed esempi per lo studio dello "stilus curiae romanae" medioevale, Roma 1941.

F. Di Capua, Tre note sull'Epistola di Dante ai Fiorentini, in «Giornale dantesco», 39 (1936), pp. 239-256.

Le dictamen dans tous ses états. Perspectives de recherche sur la théorie et la pratique de l'ars dictaminis $\left(X I^{e}-X V^{e}\right.$ siècles), a cura di B. Grévin, A.-M. Turcan-Verkerk, Turnhout 2015.

M. C. Di Franco Lilli, La Biblioteca manoscritta di Celso Cittadini, Città del Vaticano 1970.

P. Di Patre, I modi dell'intertestualità dantesca: tradizione classica e biblica in un frammento di prosa (“Ep." VI, 12-24), in «Studi Danteschi», 56 (1989), pp. 289-306.

P. Di Patre, L'arte della emulazione nelle epistole dantesche (tre reperti classico-biblici), in "Studi Danteschi», 62 (1990), pp. 323-334.

P. Di Patre, Un cursus geometrico? L'impalcatura nascosta della prosa ritmica dantesca nelle Epistole (I-XIII), in «Deutsches Dante-Jahrbuch», 85-86 (2011), pp. 279-300.

G. J. Dionisi, Serie di aneddoti. V. De' codici fiorentini, Verona 1790.

C. Dionisotti, Chierici e laici, in Geografia e storia della letteratura italiana, Torino 1977, pp. 55-88.

G. Di Scipio, St. Paul in Dante's Political Epistles, in The Presence of Pauline Thought in the Works of Dante, Lewiston 1995, pp. 143-184.

C. Dolcini, Qualcosa di nuovo su Dante. La prima dimenticata voce del suo pensiero politico (1306), in Ovidio Capitani, quaranta anni per la storia medioevale, a cura di M. C. De Matteis, Bologna 2003, 1, pp. 57-64.

P. Dronke, Dante e le tradizioni latine medioevali, Bologna 1990.

C. Dumontel, L'impresa italiana di Giovanni di Lussemburgo re di Boemia, Torino 1952.

P. Duparc, À propos des lettres de Jeanne d'Arc, in «Bulletin de la Société nationale des Antiquaires de France», 1991, pp. 71-80.

Enrico VII, Dante e Pisa a settecento anni dalla morte dell'imperatore e della monarchia (1313-2013), a cura di G. Petralia, M. Santagata, Ravenna 2016.

Enrico VII e il governo delle città italiane (1310-1313), a cura di G. M. Varanini, in «Reti Medievali Rivista», 15/1 (2014), pp. 37-155: https://doi.org/10.6092/1593-2214/417.

F. Ercole, Da Bartolo all'Althusio: Saggi sulla Storia del Diritto Pubblico del Rinascimento Italiano, Firenze 1932.

F. Ercole, Dal comune al principato. Saggi sulla storia del diritto pubblico del rinascimento italiano, Firenze 1929.

F. Ercole, Dante e l'unità nazionale [1921], Il pensiero politico di Dante, Milano 1927-1928, vol. I, pp. 79-87.

F. Ercole, L'unità politica della nazione italiana e l'Impero nel pensiero di Dante, in F. Ercole, Il pensiero politico di Dante, Milano 1927-1928, I, pp. 9-77.

F. Ercole, Il canto dell'Italia, in F. Ercole, Il pensiero politico di Dante, Milano 1927-1928, I, pp. 109-156.

F. Ercole, Il pensiero politico di Dante, Milano 1927-1928.

F. Ercole, Il sogno italico di Dante, in Il pensiero politico di Dante, Milano 1927-1928, I, pp. 89-107. 
F. Ercole, Le tre fasi del pensiero politico di Dante, in Il pensiero politico di Dante, Milano 1927-1928, II, pp. 271-407.

L'État angevin. Pouvoir, culture et société entre XIIle et XIVe siècle, Roma 1998.

G. Fagioli Vercellone, Fraticelli, Pietro, in DBI, 50 (1998).

V. Fainelli, Podestà e ufficiali di Verona dal 1305 (sec. sem.) al 1405 (prim. sem.), in «Atti e memorie dell'Accademia di Agricoltura scienze e lettere di Verona», 4/9 (1909), pp. 155-256.

E. Faini, Ruolo sociale e memoria degli Alighieri prima di Dante, in Dante attraverso $i$ documenti. I. Famiglia e patrimonio (secolo XII-1300 circa), a cura di G. Milani, A. Montefusco, in «Reti Medievali Rivista», 15/2 (2014), pp. 203-242: https://doi.org/ 10.6092/1593-2214/431.

E. Faini, Italica gens. Memoria e immaginario politico dei cavalieri-cittadini (secoli XII-XIII), Roma 2018.

P. Falzone, Desiderio della scienza e desiderio di Dio nel Convivio di Dante, Bologna 2010.

P. Falzone, Margherita di Brabante, in DBI, 70 (2008).

P. Falzone, L. Fiorentini, Note sul discorso politico dantesco tra le cancellerie imperiali di Federico II e di Enrico VII, in Dante e la retorica, a cura di L. Marcozzi, Ravenna 2017, pp. 211-45.

J. Favier, Les papes d'Avignon, Paris 2006.

C. Felisi, A.-M. Turcan-Verkerk, Les artes dictandi latines de la fin du XIe à la fin $d u$ $X I V$ siècle : un état des sources, in Le dictamen dans tous ses états. Perspectives de recherche sur la théorie et la pratique de l'ars dictaminis (XIe-XVe siècles), éds.

B. Grévin, A.-M. Turcan-Verkerk, Turnhout 2015, pp. 417-541.

E. Fenzi, Ancora a proposito dell'argomento barberiniano (una possibile eco del Purgatorio nei Documenti d'Amore di Francesco da Barberino), in «Tenzone», 6 (2005), pp. 97-120.

E. Fenzi, Ancora sulla Epistola a Moroello e sulla "montanina" di Dante (Rime, 15), in «Tenzone. Revista de la Asociación Complutense de Dantología», 4 (2003), pp. 43-84.

E. Fenzi, La Montanina e i suoi lettori, in Amor, da che convien pur ch'io mi doglia, a cura di E. Pasquini, Madrid 2009, pp. 31-84.

M. Feo, Bucolicum carmen, in Petrarca nel tempo. Tradizione lettori e immagini delle opere. Catalogo della Mostra, Arezzo, Sottochiesa di San Francesco, 22 novembre 200327 gennaio 2004, a cura di M. Feo, Pontedera 2003, pp. 279-282.

V. Fera, Storia e filologia tra Petrarca e Boccaccio, in Petrarca, l'Umanesimo e la civiltà europea, a cura di D. Coppini, M. Feo, Firenze 2012 ("Quaderni petrarcheschi», XV-XVIII, 2005-2008), pp. 369-389.

S. Ferrara, Devotissimus et amicus, in «Arzanà», 13 (2010), pp. 191-210.

S. Ferrara, D'un bannissement subi à un exil revendiqué. La construction de l'«exul» dans les Épîtres de Dante, in «Arzanà», 16-17 (2013), Écritures de l'exil dans l'Italie médiévale, éds. A. Fontes Baratto, M. Gagliano, pp. 199-213.

S. Ferrara-Pavlović, La métaphore solaire. Les trois épîtres politiques de Dante et le chant XVI $d u$ Purgatoire, in «Arzanà. Cahiers de literature médievale italienne», 12 (2007), pp. 99115.

M. Ferrari, I. Lazzarini, F. Piseri, Lettere autografe di principi “in fieri”, in Autografie dell'età minore. Lettere di tre dinastie italiane tra Quattrocento e Cinquecento, a cura di M. Ferrari, I. Lazzarini, F. Piseri, Roma 2016, pp. 11-38.

G. J. Ferrazzi, Manuale dantesco, Bassano 1877.

M. T. Ferrer Mallol, Cavalieri catalani e aragonesi al servizio dei guelfi in Italia, in «Medioevo (Cagliari)», 20 (1995), pp. 161-194. 
J. Ficker, Urkunden zur Geschichte des Römerzuges Kaiser Ludwigs des Baiern und der italienischen Verhältnisse, Innsbruck 1865.

G. Fioravanti, Università e Città. Cultura umanistica e cultura scolastica a Siena nel '400, Firenze 1980.

G. Fiori, I Malaspina: castelli e feudi nell'Oltrepò piacentino, pavese, tortonese, Piacenza 1995.

G. Fiori, I Malaspina di Pregola ed i feudi imperiali sulla sinistra del Trebbia, in «Archivio Storico delle Province Parmensi», 16 (1964), pp. 261-342.

J. Fohlen, Les manuscrits classiques dans le fonds Vatican latin d'Eugène IV (1443) à Jules III (1550), in «Humanistica Lovaniensia», 34A (1985), pp. 1-51.

P. Fohlen, La bibliothèque du pape Eugène IV (1431-1447). Contribution à l'histoire du fonds Vatican latin, Città del Vaticano 2008.

A. Fontes Baratto, Le diptyque montanino de Dante, in «Arzanà. Cahiers de Littérature médiévale italienne», 12 (2007), Poésie et épistolographie dans l'Italie médiévale, pp. 65-97.

A. Fontes Baratto, Linguaggio biblico e missione imperiale nell'Epistola $V$ di Dante, in Enrico VII, Dante e Pisa, Ravenna 2016, pp. 223-42.

F. Forti, La transumptio nei dettatori bolognesi e in Dante, in Dante e Bologna nei tempi di Dante, Bologna 1967, pp. 127-49.

Francesco Novati. Inventario del fondo conservato presso la Società storica lombarda, a cura di E. Colombo, Bologna 1997.

G. Francesconi, La signoria pluricittadina di Castruccio Castracani. Un'esperienza politica "costituzionale" nella Toscana di primo Trecento, in Le signorie cittadine in Toscana. Esperienze di potere e forme di governo personale (secoli XIII-XV), a cura di A. Zorzi, Roma 2013, pp. 149-168.

M. E. Franke, Kaiser Heinrich VII. im Spiegel der Historiographie. Eine faktenkritische und quellenkundliche Untersuchung ausgewählter Geschichtsschreiber der ersten Hälfte des 14. Jahrhunderts, Köln-Weimar-Wien 1992.

A. Frugoni, Divinae Sapientiae, in ED, 2.

E. Fumagalli, Appunti sulla biblioteca dei Visconti e degli Sforza nel castello di Pavia, in «Studi petrarcheschi», n.s. 7 (1990), pp. 93-211.

F. Gabrieli, Il canto VI del Purgatorio, in Nuove letture dantesche, Firenze 1969, pp. 333-349.

F. Gagliardi, L'«alto Arrigo» nelle epistole dantesche del 1310-11. Modelli biblici e classici, in «La Cultura», 45/1 (2007), pp. 133-142.

G. Galasso, Il Regno di Napoli: il mezzogiorno angioino e aragonese, Torino $1993^{2}$.

S. Gallick, Medieval Rhetorical Arts in England and the Manuscript Traditions, in «Manuscripta», 18 (1974), pp. 67-95.

A. Gamberini, La memoria dei gentiluomini. I cartulari di lignaggio alla fine del medioevo, in Scritture e potere. Pratiche documentarie e forme di governo nell'Italia tardomedievale (XIV-XV secolo), a cura di I. Lazzarini, in «Reti medievali. Rivista», 9 (2008), pp. 1-16.

P. Garbini, Francesco Petrarca fra l'arte della regola e la regola d'arte, in Dall'ars dictaminis' al preumanesimo? Per un profilo letterario del secolo XIII, a cura di F. Delle Donne, F. Santi, Firenze 2013, pp. 173-86.

L. Gargan, Scuole di grammatica e Università a Padova tra Medioevo e Umanesimo, in "Quaderni per la storia dell'Università di Padova», 33 (2000), pp. 9-26 (poi in Gargan, Libri e maestri tra Medioevo e Umanesimo, Messina 2011, pp. 539-556).

L. Gargan, Dante e Giovanni del Virgilio: le "Egloghe", in «Giornale Storico della Letteratura Italiana», 187 (2010), pp. 342-369 (poi in Gargan, Dante, la sua biblioteca e lo Studio di Bologna, Roma-Padova 2014, pp. 112-141). 
A. Gaudenzi, Sulla cronologia delle opere dei dettatori Bolognesi da Buoncompagno a Bene di Lucca, in «Bullettino dell'Istituto storico italiano», 14 (1895), pp. 118-150.

A. Gauert, Albrecht I, in Neue Deutsche Biographie, I, Berlino 1953, pp. 152-54.

S. Gentili, Girolami, Remigio de', in DBI, 56 (2006).

E. Gerini, Memorie storiche d'illustri scrittori e di uomini insigni dell'antica e moderna Lunigiana, Massa 1829.

F. Giancotti, Ricerche sulla tradizione manoscritta delle sentenze di Publilio Siro, MessinaFirenze 1963.

W. Goez, Die Einstellung zum Tode im Mittelalter, in Der Grenzbereich zwischen Leben und Tod, Göttingen 1976.

G. Gorni, Dante. Storia di un visionario, Roma-Bari 2009.

G. Gorni, La canzone "montanina", in Le "Rime" di Dante, a cura di M. Picone, in «Letture Classensi», XXIV, Ravenna 1995, pp. 129-150.

M. Gragnolati, Authorship and Performance in Dante's "Vita nova», in Aspects of the Performative in Medieval Culture, a cura di M. Gragnolati, A. Suerbaum, Berlin-New York 2010, pp. 123-140.

M. Gragnolati, Una performance senza gerarchia: la riscrittura bi-stabile della Vita nova, in Vita nova, Fiore, Epistola XIII, a cura di M. Gragnolati, L. C. Rossi, P. Allegretti, N. Tonelli, A. Casadei. Firenze 2018, p. 67-86.

T. Grasilier, Cartulaires inédits de la Saintonge, II. Cartulaire de l'Abbaye royale de NotreDame de Saintes de l'ordre de saint Bénoit, Niort 1871.

E. Graziosi, Dante a Cino: sul cuore di un giurista, in «Letture Classensi», 26 (1997), pp. 55-91.

L. Green, Castruccio Castracani. A study on the origins and character of a fourteenth-century Italian despotism, Oxford 1986.

L. Green, Chronicle into history: an essay on the interpretation of history in the Florentine fourteenth-century chronicles, Cambridge 1972.

B. Grévin, De l'ornementation à l'automatisme. Cursus rythmique et écriture semi-formulaire (XII ${ }^{e}$ XIV $V^{e}$ s.), Rythmes et croyances au Moyen Âge, a cura di M. Formarier, J.-C. Schmitt, Bordeaux 2014, pp. 81-102.

B. Grévin, Héritages culturels des Hohenstaufen. Volgarizzamenti de lettres et discours de Fréderic Il et de ses adversaires. Problèmes d'interprétation, in «Mélanges de l'École Française de Rome», 114/2 (2002), pp. 981-1043.

B. Grévin, L'ars dictaminis, discipline hégémonique (fin XIIe-début XIVe s.). Mutations et idéologisation d'un art d'écrire médiéval, entre trivium, droit et exégèse, in Frontières des savoirs en Italie à l'époque des premières universités (XIII $-X V^{e}$ siècle), a cura di J. Chandelier, A. Robert, Rome 2015, pp. 17-80.

B. Grévin, L'empire d'une forme. Réflexions sur la place du cursus dans les pratiques d'écriture européennes à l'automne du Moyen Âge (XIII $-X V^{e}$ siecle), in Parva pro magnis munera. Études de littérature tardo-antique et médiévale offertes à François Dolbeau par ses élèves, a cura di M. Goullet, Turnhout 2009, pp. 857-881.

B. Grévin, Les frontières du dictamen. Structuration et dynamiques d'un espace textuel médiéval (XIII'XVe s.), in «Interfaces», 1 (2015), pp. 142-169.

B. Grévin, «Linguistic mysteries of the state». Réflexions sur la tension entre intelligibilité et sacralisation dans la rhétorique politique latine aux XIII'e et XIVe siècles, in La langue des actes. Actes du XI $\mathrm{I}^{\mathrm{e}}$ congrés international diplomatique, a cura di 0 . Guyotjeannin, Paris 2003: <http://elec.enc.sorbonne.fr/CID2003/grevin.

B. Grévin, Métaphore et vérité: la transumptio, clé de voûte de la rhétorique au XIII siècle, in La vérité. Vérité et crédibilité: construire la vérité dans le système de communication de l'Occident (XIII $-X V I I^{e}$ siècle), a cura di J.-P. Genet, Paris 2015, pp. 149-82. 
B. Grévin, Rhétorique du pouvoir médiéval. Les lettres de Pierre de la Vigne et la formation du langage politique européen (XIII ${ }^{e} X V^{e}$ siècle), Rome 2008.

B. Grévin, Zur Benutzung der päpstlichen Briefsammlungen des 13. Jahrhunderts im Spätmittelalter. Das Beispiel der französischen Königskanzlei, in Kuriale Briefkultur. Gestaltung Überlieferung Rezeption, a cura di T. Broser, A. Fischer, M. Thumser, WienKöln-Weimar 2015, pp. 313-34.

P. Grillo, Milano guelfa (1302-1310), Roma 2013.

M. Grimaldi, Per lo studio della poesia italiana del Due e del Trecento. "Versi a un destinatario" di Claudio Giunta, in «Nuova Rivista di Letteratura Italiana», 18/2 (2015), pp. 11-22.

Grupo Tenzone, “Amor, da che convien pur ch'io mi doglia”, a cura di E. Pasquini, Departamento de Filologìa Italiana UCM-Asociaciòn Complutense de Dantologìa, Barcellona 2009.

P. Guiraud, L'argot, Paris 1956.

G. G. Guzman, Manuscripts of the "Speculum historiale" of Vincent of Beauvais in the Vatican Library, in «Manuscripta», 32 (1988), pp. 20-27.

Handschriftenverzeichnis zur Briefsammlung des Thomas von Capua, auf Grundlage der Vorarbeiten von H. M. Schaller bearb. v. K. Stöbener, M. Thumser, München 2017 (MGH, Hilfsmittel).

J. Hankins, Coluccio Salutati e Leonardo Bruni, in Il contributo italiano alla storia del pensiero, a cura di M. Ciliberto, Roma 2012, pp. 85-94.

R. Härtel, «Autodenominazione» $e$ «allodenominazione» nei secoli centrali del medioevo (Aquileia, sec. XII e XIII), in «Mélanges de l'école française de Rome. Moyen âge Temps modernes», 106 (1994), 2, pp. 331-341.

R. Härtel, Die Italienpolitik König Johanns von Böhmen, in Johann der Blinde, Graf von Luxemburg, König von Böhmen 1296-1346, a cura di M. Pauly, Luxembourg 1997, pp. 363-382.

F. Hartmann, Ars dictaminis: Briefsteller und verbale Kommunikation in den italienischen Stadtkommunen des 11. bis 13. Jahrhunderts, Ostfildern 2013.

P. S. Hawkins, «Descendit ad inferos», in Dante's Testaments: Essays in Scriptural Imagination, Stanford 1999, pp. 99-124.

M.-L. Heckmann, Stellvertreter, Mit- und Ersatzherrscher. Regenten, Generalstatthalter, Kurfürsten und Reichsvikare in Regnum und Imperium vom 13. bis zum frühen 15. Jahrhundert, Warendorf 2002.

M. Heidemann, Heinrich VII (1308-1313). Kaiseridee im Spannungsfield von Staufischer Universalherrschaft und frühneuzeitlicher Partikularautonomie, Warendorf 2008.

D. Heilbronn, Dante's Gate of Dis and the Heavenly Jerusalem, in «Studies in Philology», 72 (1975), pp. 167-92.

E. Heller, Der kuriale Geschäftsgang in den Briefen des Thomas v. Capua, in «Archiv für Urkundenforschung», 13 (1935), pp. 198-318.

P. Herde, Aspetti retorici dell'epistolario di Riccardo da Pofi: documenti papali autentici o esercitazioni letterarie?, in Dall'“ars dictaminis" al preumanesimo? Per un profilo letterario del secolo XIII, a cura di F. Delle Donne, F. Santi, Firenze 2013, pp. 117-41.

P. Herde, Authentische Urkunde oder Stilübung? Papsturkunden in der Briefsammlung des Richard von Pofi, in Kuriale Briefkultur im späteren Mittelalter. Gestaltung Überlieferung Rezeption, a cura di T. Broser, A. Fischer, M. Thumser, Köln-Weimar-Wien 2015.

P. Herde, Guelfen und Gibellinen, in Friedrich II.: Tagung des Deutschen Historischen Instituts in Rom im Gedenkjahr 1994, a cura di A. Esch, N. Kamp, Tübingen 1996, pp. 50-65. 
P. Herde, Guelfen und Neoguelfen, in Gesammelte Abhandlungen und Aufsätze, vol. I: Von Dante zum Risorgimento, Stuttgart 1997, pp. 259-398.

P. Hibst, Utilitas publica, gemeiner Nutz, Gemeinwohl: Untersuchungen zur Idee eines politischen Leitbegriffes von der Antike bis zum späten Mittelalter, Frankfurt 1991.

W. Hoffa, Textkritische Untersuchungen zu Senecas Tragödien, in «Hermes», 49 (1914), pp. 464-475.

R. Hollander, Dante as Uzzah? («Purg.» X 57, and «Ep.»XI 9-12, in Sotto il segno di Dante. Scritti in onore di Francesco Mazzoni, a cura di L. Coglievina, D. De Robertis, Firenze 1998, pp. 143-51.

C. E. Honess, «Ritornerò poeta»: Florence, Exile, and Hope, in «Se mai continga ...»: Exile, Politics and Theology in Dante, a cura di C. E. Honess, M. Treherne, Ravenna 2013, pp. 85-103.

A. Hortis, Studj sulle opere latine del Boccaccio con particolare riguardo alla storia della erudizione nel Medio Evo e alle letterature straniere, Trieste 1879.

N. Housley, The Italian Crusades. The Papal-Angevin Alliance and the Crusade against Christian Lay Powers, Oxford 1982.

A. Iannucci, Dottrina e allegoria in Inf. VIII, 67-IX, 105, in Dante e le forme dell'allegoresi, a cura di M. Picone, Ravenna 1987, pp. 99-124.

Imago et descriptio Tusciae: la Toscana nella geocartografia dal XV al XIX secolo, a cura di L. Rombai, Firenze-Venezia 1993.

G. Indizio, "Con la forza di tal che testè piaggia»: storia delle relazioni tra Bonifacio VIII, Firenze e Dante, in «Italianistica», 39 (2010), pp. 69-96 (poi in G. Indizio, Problemi di biografia dantesca, Ravenna 2013, pp. 57-91).

G. Indizio, Gli argomenti esterni per la pubblicazione dell'Inferno e del Purgatorio, in Problemi di biografia dantesca, Ravenna 2013, pp. 223-234.

G. Indizio, La profezia di Cacciaguida: note sulla biografia di Dante nei primi tempi dell'esilio, in «Rivista di studi danteschi», 16 (2016), pp. 290-323.

G. Indizio, Problemi di biografia dantesca, Ravenna 2014.

G. Indizio, Sul mittente dell'“Epistola" I di Dante (e la cronologia della I e della II), in «Rivista di Studi Danteschi», 2 (2002), 1, pp. 134-145 (poi in Indizio, Problemi di biografia dantesca, Ravenna 2014, pp. 189-201).

G. Inglese, Dante (?) a Cangrande. Postille, in «Giornale Storico della Letteratura Italiana», 131 (2014), pp. 121-123.

G. Inglese, Vita di Dante. Una biografia possibile, Roma 2015.

D. Internullo, Ai margini dei giganti: la vita intellettuale dei Romani nel Trecento (13051367 ca.), Roma 2016.

R. Jacoff, Dante, Geremia, e la problematica profetica, in Dante e la Bibbia, a cura di G. Barblan, Firenze 1988, pp. 113-23.

A. Jacomuzzi, Il palinsesto della retorica e altri saggi danteschi, Firenze 1972.

T. Janson, Prose Rhythm in Medieval Latin from the 9th to the 13th Century, Stockholm 1975.

E. Jordan, Les origines de la domination angevine en Italie, Paris 1909.

P. Jugie, Un Quercynois à la cour pontificale d'Avignon: le cardinal Bertrand du Pouget, in La papauté d'Avignon et le Languedoc, Toulouse 1991, pp. 69-95.

E. Kantorowicz, An "Autobiography" of Guido Faba, in «Medieval and Renaissance Studies», 1 (1941-3), pp. 253-80; ristampato in Kantorowicz, Selected Studies, New York 1965, pp. 194-212.

H. Kantorowicz, Über die dem Petrus de Vineis zugeschriebenen "Arenge", in «Mitteilungen des Instituts für Österreichische Geschichtsforschung», 30 (1909). 
M. H. Keen, The Political Thought of the Fourteenth-Century Civilians, in Trends in Medieval Political Thought, ed. Beryl Smalley, Oxford 1965, pp. 105-26.

S. Kelly, The New Solomon: Robert of Naples (1309-1343) and Fourteenth-Century Kingship, Leiden-Boston 2003.

M. S. Kempshall, The Common Good in Late Medieval Political Thought, Oford 1999.

J. Kirshner, Bartolo of Sassoferrato's De Tyranno and Sallutio Buonguglielmi's Consilium on Niccolò Fortebracci's Tyranny in Città di Castello, in «Medieval Studies», 68 (2006), pp. 303-331.

C. König-Pralong, La philosophie de Dante dans l'ombre de la Comédie: de Brucker à Witte, in La filosofia e la sua storia. Studi in onore di Gregorio Piaia, a cura di M. Forlivesi, M. Longo, G. Micheli, Padova 2017, II, pp. 15-28.

R. Krautheimer, The Times of Gregory the Great, in Rome Profile of a City, 312-1308, New Jersey 1983, pp. 59-87.

P. O. Kristeller, Iter Italicum. A Finding List of Uncatalogued or Incompletely Catalogued Humanistic Manuscripts of the Renaissance in Italian and other Libraries, London-Leiden 1963-1997.

P. O. Kristeller, Matteo de' Libri, Bolognese notary of the thirteenth century, and his "Artes dictaminis", in Miscellanea Giovanni Galbiati, Milano 1951, vol. II, pp. 283-320.

P. O. Kristeller, Un'“Ars dictaminis” di Giovanni del Virgilio, in «Italia medioevale e umanistica», 4 (1961), pp. 179-200.

T. Kuehn, Conflicting Conceptions of Property in Quattrocento Florence: A Dispute over Ownership in 1425-26, in Law, Family, \& Women: Toward a Legal Anthropology of Renaissance Italy, Chicago 1991, pp. 101-126.

G. La Mantia, Il primo documento in carta (contessa Adelaide, 1109) esistente in Sicilia e rimasto finora sconosciuto, Palermo 1908.

A. Lanci, Porco, in ED, 4.

A. Lancia, Chiose alla "Commedia", a cura di L. Azzetta, Roma 2012.

F. Landogna, Giovanni di Boemia e Carlo di Lussemburgo signori di Lucca, in «Nuova rivista storica», 12 (1928), pp. 53-72.

C. D. Lanham, Salutatio Formulas in Latin Letters to 1200, München 1975.

C. M. de La Roncière, Diversi conti Guidi dai loro testamenti (1300-1400): pietà, proprietà, vanagloria, in La lunga storia di una stirpe comitale. I conti Guidi tra Romagna e Toscana, Atti del Convegno (Poppi-Modigliana 2003), a cura di F. Canaccini, Firenze 2008, pp. 445-465.

Brunetto Latini, La Rettorica, a cura di Francesco Maggini, Firenze 1915.

Brunetto Latini, Poesie, a cura di S. Carrai, Torino 2015.

I. Lazzarini, I Gonzaga e gli Este tra XV e XVI secolo, in Autografie dell'età minore. Lettere di tre dinastie italiane tra Quattrocento e Cinquecento, a cura di M. Ferrari, I. Lazzarini, F. Piseri, Roma 2016, pp. 39-67.

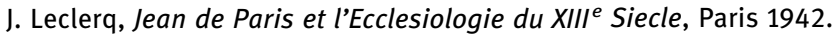

G. Ledda, Modelli biblici e identità profetica nelle epistole di Dante, in «Lettere italiane», LX/1 (2008), pp. 18-41.

G. Ledda, Modelli biblici e profetismo nelle «Epistole» di Dante, in Sotto il cielo delle Scritture. Bibbia, retorica e letteratura religiosa (secc. XIII-XVI), Atti del Colloquio organizzato dal Dipartimento di Italianistica dell'Università di Bologna (Bologna, 1617 novembre 2007), a cura di C. Delcorno, G. Baffetti, Firenze 2009, pp. 57-78.

G. Ledda, Un bestiario politico nelle Epistole di Dante, in «Italianistica», 44/2 (2015), pp. 161-79. 
P. Lehmann, Eine Geschichte der alten Fuggerbibliotheken, Tübingen 1960, vol. II. Quellen und Rekonstruktionen.

L. Leonardi, Guittone e dintorni. Arezzo, lo Studium e la prima rivoluzione della poesia italiana, in 750 anni degli Statuti universitari aretini. Atti del Convegno internazionale su origini, maestri, discipline e ruolo culturale dello Studium di Arezzo (Arezzo, 1618 febbraio 2005), a cura di F. Stella, Firenze 2006, pp. 205-223.

É. G. Léonard, Les Angevins de Naples, Paris 1954.

J. Leonhard, Genua und die päpstliche Kurie in Avignon (1305-1378). Politische und diplomatische Beziehungen im 14. Jahrhundert, Frankfurt 2013.

R. E. Lerner, Ornithological propaganda: the fourteenth-century denigration of Dominicans, in Politische Reflexion in der Welt des späten Mittelalters = Political thought in the age of scholasticism: essays in honour of Jürgen Miethke, ed. M. Kaufhold, Leiden 2004, pp. 171-191.

V. Licitra, La 'Summa de arte dictandi' di maestro Goffredo, in «Studi medievali» 3 (1966), pp. 865-913.

Limitation and Prescription. A Comparative Legal History, a cura di H. Dondorp, D. Ibbetson, E. Schrage, Berlin 2019.

G. Lindholm, Studien zum Mittellateinischen Prosarhythmus. Seine Entwicklung und sein Abklingen in der Briefliteratur Italiens, Stockholm 1963.

R. Lokaj, Dante's Comic Reappraisal of Petrine Primacy, in «Critica del testo», XIV/2 (2011), pp. 109-146.

R. Lokaj, De sotio, sive Petrarch's Use of Livy in Fam. IV 1, in «Euphrosyne», 33 (2005), pp. 53-65.

R. Lokaj, L'emergenza di un'“ars dictaminis" dantesca: L'“Epistola” II, in "Studi danteschi», 79 (2014), pp. 1-38.

C. Lorenzi, Volgarizzamenti di epistole in un codice trecentesco poco noto (Barb. lat. 4118), in «Linguistica e letteratura Open», 42 (2017), pp. 315-58, online: <https:// www.libraweb.net/articoli.php?chiave $=201701602 \&$ rivista $=16$ >.

G. Lumia, Aspetti del pensiero politico di Dante, Milano 1965.

La lunga storia di una stirpe comitale. I conti Guidi tra Romagna e Toscana, Atti del Convegno (Poppi-Modigliana 2003), a cura di F. Canaccini, Firenze 2008.

A. P. MacGregor, The Manuscripts of Seneca's Tragedies: A Handlist, in Aufstieg und Niedergang der römischen Welt, hrsg. von H. Temporini, W. Haase, Berlin-New York 1985, II/32.2, pp. 1134-1241.

Mächtige Frauen? Königinnen und Fürstinnen im europäischen Mittelalter (11.-14. Jahrhundert). Zur Einführung, a cura di C. Zey, in «Vorträge und Forschungen», 81 (2015).

M. Madero, Penser la physique du pouvoir. La possession de la juridiction dans les commentaires d'Innocent IV et d'Antonio de Budrio à la décrétale "Dilectus", in «Clio \& Themis», 11 (2016), online.

D. Maffei, La donazione di Costantino nei giuristi medievali, Milano 1964.

W. Maleczek, Vent'anni dopo. L'autenticità del Testamento di Chiara: una questione chiusa?, in «Franciscana. Bollettino della Società internazionale di studi francescani», 20 (2018), pp. 51-133.

J.-C. Maire Vigueur, Il comune romano, in Storia di Roma dall'antichità a oggi, vol. II, Roma medievale, a cura di A. Vauchez, Roma-Bari 2001, pp. 117-157.

J.-C. Maire Vigueur, Nello Stato della Chiesa: da una pluralità di circuiti al trionfo del Guelfismo, in I podestà dell'Italia comunale, a cura di J. C. Maire Vigueur, Roma 2000, 
vol. II Nord, in Un itinéraire européen: Jean l'Aveugle, comte de Luxembourg et roi de Bohême 1296-1346, dir. M. Margue, Luxembourg 1996, pp. 87-109.

E. Malato, Dante, Roma 1999.

E. Malato, Il mito di Dante dal Tre al Novecento, in «Per correr miglior acque ...». Bilanci e prospettive degli studi danteschi alle soglie del nuovo millennio, Roma 2001, pp. 3-40.

A. Mancini, Un nuovo manoscritto dell'Epistola ad Arrigo, in «Studi danteschi», 24 (1939), p. 197.

D. Mancusi-Ungaro, Dante and the Empire, New York 1987.

A. Manfredi, I codici latini di Niccolò V. Edizione degli inventari e identificazione dei manoscritti, Città del Vaticano 1994.

N. Mann, The Making of Petrarch's "Bucolicum Carmen": A contribution to the history of the text, in «Italia medioevale e umanistica», 20 (1977), pp. 127-182.

N. Mann, L'unico esemplare di un commento anonimo al "Bucolicum carmen", in Codici latini del Petrarca nelle biblioteche fiorentine. Catalogo della Mostra, Biblioteca Medicea Laurenziana, Firenze, 19 Maggio-30 Giugno 1991, a cura di M. Feo, Firenze 1991, pp. 81-82 n. 42.

N. Mann, Bucolicum carmen, in Codici latini del Petrarca nelle biblioteche fiorentine. Catalogo della Mostra, Biblioteca Medicea Laurenziana, Firenze, 19 Maggio-30 Giugno 1991, a cura di M. Feo, Firenze 1991, pp. 423-425 sch. PP 10.

N. Mann, Il "Bucolicum carmen" e la sua eredità, in "Quaderni petrarcheschi», 9-10 (19921993), pp. 513-534 (poi in N. Mann, I manoscritti del "Bucolicum carmen" e dei suoi commenti, in Petrarca nel tempo. Tradizione lettori e immagini delle opere. Catalogo della Mostra, Arezzo, Sottochiesa di San Francesco, 22 novembre 2003-27 gennaio 2004, a cura di M. Feo, Pontedera 2003, pp. 288-290).

I Manoscritti del fondo S. Pantaleo, a cura di V. Jemolo, M. Morelli, Roma 1977.

R. Manselli, Cangrande e il mondo ghibellino nell'ttalia settentrionale alla venuta di Arrigo VII, in R. Manselli, Scritti sul medioevo, Roma 1994, pp. 293-306.

R. Manselli, Carlo Martello d'Angiò, re titolare d'Ungheria, in Enciclopedia Dantesca, Roma 1970-1978.

R. Manselli, Profetismo, in Enciclopedia Dantesca, Roma 1970-1978.

Les manuscrits classiques latins de la Bibliothèque Vaticane, catalogue établi par É. Pellegrin, F. Dolbeau, J. Fohlen, J. Y. Tilliette, Paris-Roma 1991, vol. III/1. Fonds Vatican latin, 224-2900.

Les manuscrits classiques latins de la Bibliothèque Vaticane, catalogue établi par É. Pellegrin, édité par A. V. Gilles-Raynal, F. Dolbeau et al., Cité du Vatican-Paris 2010, vol. III/2. Fonds Vatican latin, 2901-14740.

G. P. Marchi, Dante nella Verona scaligera, in Dante Alighieri, Commedia. Biblioteca Universitaria di Budapest, Codex Italicus 1. Studi e ricerche, a cura di G.P.M. e Jozsef Pal, Verona, 2006, pp. 25-33.

G. P. Marchi, Dante e Petrarca nella Verona scaligera, in «Atti e memorie dell'Accademia di agricoltura, scienze e lettere di Verona», CLXXXI (2004-2005, ma 2009), pp. 259-275.

G. P. Marchi, «Equis armisque vacantem». Postille interpretative a un passo dell'epistola di Dante a Oberto e Guido da Romena, in «Testo», 32 (2011), pp. 239-252.

S. Marchitelli, Da Trevet alla stampa: le tragedie di Seneca nei commenti tardomedievali, in Le commentaire entre tradition et innovation. Actes du colloque international de l'Institut des traditions textuelles (Paris et Villejuif, 22-25 septembre 1999), publiés sous la direction de M. 0. Goulet-Cazé, Paris 2000, pp. 137-145. 
L. Marcozzi, Petrarca testimone dell'esilio di Dante, in «Letture classensi», 44 (2015), pp. 44-97.

E. Marguin-Hamon, Arts poétiques médiolatins et arts de seconde rhétorique: convergences, in «Revue d'Histoire des Textes», 6 (2011), pp. 99-137.

A. Mariani, Moderno, in ED, 3.

A. Marigo, Mistica e scienza nella «Vita nuova», Padova 1914.

G. Martellotti, Censura severior, in «Italia medioevale e umanistica», 17 (1974), pp. 244-247 (poi in Martellotti, Scritti petrarcheschi, a cura di M. Feo, S. Rizzo, Padova 1983, pp. 419-423).

R. L. Martinez, Cavalcanti “Man of Sorrows" and Dante, in Guido Cavalcanti tra i suoi lettori, a cura di M. L. Ardizzone, Fiesole 2003, pp. 187-212.

R. L. Martinez, Cleansing the Temple: Dante, Defender of the Church, Buffalo (NY) 2017.

R. L. Martinez, "Vadam ad portas inferi": la catabasi dantesca e la liturgia, in Lecturae Dantis: Dante oggi e letture dell'Inferno, a cura di S. Cristaldi, in «Le forme e la storia: Rivista di Filologia Moderna», 9/2 (2016), pp. 105-126.

L. Mascetta-Caracci, Il «cursus» ritmico, la critica dei testi medioevali e l'«Epistolario» di Dante Alighieri, in «La Biblioteca degli Studiosi», 2 (1910), pp. 174-88, 219-223.

G. Masi, I banchieri fiorentini nella vita politica della città sulla fine del Duecento, in «Archivio giuridico "Filippo Serafini”», 105 (1931), pp. 57-89.

S. Maspoli Genetelli, Filosofia politica in forma di lettera, in «Freiburger Zeitschrift für Philosophie und Theologie», 53 (2006), pp. 367-385.

D. Masson, La Broce ou la Brosse (Pierre de), in Dictionnaire de Biographie Française, XVIII (1994), coll. 1423-1425.

P. Mazzamuto, L'epistolario di Pier della Vigna e l'opera di Dante, in Atti del convegno di studi su Dante e la Magna Curia (Palermo-Catania-Messina, 7-11 novembre 1965), Palermo 1967, pp. 201-255.

G. Mazzatinti, F. Pintor, Inventari dei manoscritti delle biblioteche d'Italia, Forlì 1901, XI.

F. Mazzoni, Con Dante per Dante: saggi di filologia ed ermeneutica dantesca, a cura di G. C. Garfagnini, E. Ghidetti, S. Mazzoni, Roma 2014-2016.

F. Mazzoni, Dante e la terra Casentinese, in «Rotary Club Firenze», IV (1985), pp. 8-15 (rist. anast. in F. Mazzoni, Con Dante per Dante: saggi di filologia ed ermeneutica dantesca, a cura di G. C. Garfagnini, E. Ghidetti, S. Mazzoni, Roma 2014-2016, I, pp. 97-109).

F. Mazzoni, Filologia dantesca all'ombra del Salutati, in «Studi Danteschi», 70 (2005), pp. 193-236.

F. Mazzoni, Il codice S(enese) dell'Epistola dantesca ad Arrigo, in Tradizione classica e letteratura umanistica. Per Alessandro Perosa, a cura di R. Cardini, E. Garin, L. Cesarini Martinelli, G. Pascucci, Roma 1985, vol. II, pp. 685-691 (rist. anast. in F. Mazzoni, Con Dante per Dante: saggi di filologia ed ermeneutica dantesca, a cura di G. C. Garfagnini, E. Ghidetti, S. Mazzoni, Roma 2014-2016, IV, pp. 281-288).

F. Mazzoni, L'edizione delle opere latine minori, in Atti del Convegno internazionale di studi danteschi, Ravenna, 10-12 settembre 1971, Ravenna 1979, pp. 129-166 (rist. anast. in F. Mazzoni, Con Dante per Dante: saggi di filologia ed ermeneutica dantesca, a cura di G. C. Garfagnini, E. Ghidetti, S. Mazzoni, Roma 2014-2016, IV, pp. 71-108).

F. Mazzoni, Le Ecloghe e le Epistole, in «Città di Vita», 20 (1965), pp. 395-430.

F. Mazzoni, Le epistole di Dante, in Conferenze aretine 1965, Arezzo-Bibbiena 1966, pp. 47100 (rist. anast. con correzioni d'autore in F. Mazzoni, Con Dante per Dante: saggi di filologia ed ermeneutica dantesca, a cura di G. C. Garfagnini, E. Ghidetti, S. Mazzoni, Roma 2014-2016, IV, pp. 277-330). 
F. Mazzoni, Moderni errori di trascrizione nelle epistole dantesche conservate nello Zibaldone Laurenziano, in Gli Zibaldoni di Boccaccio. Memoria, scrittura, riscrittura. Atti del Seminario internazionale di Firenze-Certaldo (26-28 aprile 1996), a cura di M. Picone, C. Cazalé Bérard, Firenze 1998, pp. 315-325 (rist. anast. in F. Mazzoni, Con Dante per Dante: saggi di filologia ed ermeneutica dantesca, a cura di G. C. Garfagnini, E. Ghidetti, S. Mazzoni, Roma 2014-2016, IV, pp. 333-343).

F. Mazzoni, Riflessioni sul testo dell'Epistola VII di Dante: vi fu un archetipo?, in «Filologia e critica», 15 (1990), pp. 436-44 (rist. anast. in F. Mazzoni, Con Dante per Dante: saggi di filologia ed ermeneutica dantesca, a cura di G. C. Garfagnini, E. Ghidetti, S. Mazzoni, Roma 2014-2016, IV, pp. 289-299).

F. Mazzoni, Un autografo di Dante?, in «La Stampa» del 10 marzo 1965.

C. E. Meek, Della Faggiola Uguccione, in DBI, 36 (1988).

G. G. Meersseman, Seneca maestro di spiritualità nei suoi opuscoli apocrifi dal XII al XV secolo, in «Italia medioevale e umanistica», 16 (1973), pp. 43-135.

A. C. Megas, O prooumanistikos kyklos tēs Padouas (Lovato Lovati Albertino Mussato) kai oi tragōdies tou L. A. Seneca. Diatribē epi didaktoria, Thessalonikē 1967.

P. Mehtonen, Obscure language, unclear literature. Theory and practice from Quintilian to the Enlightenment, Helsinki 2003.

E. M. Meijers, Usucapione e prescrizione contro lo stato, in Scritti per la beatificazione di Contardo Ferrini, Milano 1949, IV, pp. 202-217.

S. Menache, Clement V, New York 1998.

P. V. Mengaldo, Cursus, in $E D, 2$.

A. Menniti Ippolito, Dente, Vitaliano, in DBI, 38 (1990).

S. Menzinger (a cura di), Cittadinanze medievali. Dinamiche di appartenenza a un corpo comunitatio, Roma 2017.

S. Menzinger, Dante, la Bibbia, il diritto. Sulle tracce di Uzzà nel pensiero teologico-giuridico medievale in «Dante Studies», 133 (2015), pp. 122-146.

S. Menzinger, Diritti di cittadinanza nelle quaestiones giuridiche duecentesche e iniziotrecentesche (I), in «Mélanges de l’École française de Rome. Série Moyen Âge», 125/2 (2013): 〈http://journals.openedition.org/mefrm/1468>.

P. A. Menzio, Il traviamento intellettuale di Dante Alighieri, secondo Witte, Scartazzini ed altri critici e commentatori del sec. 19, Livorno 1903.

P. Merati, L'attività documentaria di Enrico VII in Italia, in Enrico VII e il governo delle città italiane (1310-1313), a cura di G. M. Varanini, in «Reti medievali. Rivista», 15/1 (2014), pp. 1-29: https://doi.org/10.6092/1593-2214/411

W. Meyer, Über Ursprung und Blute der mittellateinischen Dichtungsformen, in Gesammelte Abhandlungen zur mittellateinischen Rythmik, I, Berlin 1905, pp. 1-58.

M. Miegge, Introduzione, in Girolamo Savonarola da Ferrara all'Europa, a cura di G. Fragnito, M. Miegge, Firenze 2001, pp. 301-311.

L. Miglio, "Perch'io ho charestia di chi scriva». Delegati di scrittura in ambiente mediceo, in L. Miglio, Governare l'alfabeto. Donne, scrittura e libri nel Medioevo, Roma 2008, pp. 133-162.

M. Miglio, Il senato in Roma medievale, in Il Senato nella storia. Il senato nel Medioevo e nella prima età moderna, Roma 1997, pp. 117-172.

R. Migliorini Fissi, Dante e il Casentino, in Dante e le città dell'esilio. Atti del Convegno internazionale di Studi, Ravenna, 11-13 settembre 1987, a cura di G. Di Pino, Ravenna 1989, pp. 115-146. 
R. Migliorini Fissi, La lettera pseudo-dantesca a Guido da Polenta: Edizione critica e ricerche attributive, in «Studi Danteschi», 46 (1969), pp. 101-272.

A. Mikkel, Cursus in Dante Alighieri's prose books "De vulgari eloquentia", "De Monarchia" and "Convivio", in "Studia Metrica et Poetica», $3 / 1$ (2016), pp. 105-120.

G. Milani, Appunti per una riconsiderazione del bando di Dante, in «Bollettino di italianistica», 8 (2011), pp. 42-70.

G. Milani, Dante politico fiorentino, in Dante attraverso i documenti. II. Presupposti e contesti dell'impegno politico a Firenze (1295-1302), a cura di G. Milani, A. Montefusco, in «Reti Medievali Rivista», 18 (2017), pp. 511-563: https://doi.org/10.6092/1593-2214/5153.

G. Milani, I contesti politici e sociali, in G. Inglese, Vita di Dante. Una biografia possibile, Roma 2015, pp. 169-191.

G. Milani, L'esclusione dal Comune. Conflitti e bandi politici a Bologna e in altre città italiane tra XII e XIV secolo, Roma 2003.

G. Milani, Rovesci della cittadinanza. Appunti per una storia comparata di bandi e scomuniche nel medioevo in Cittadinanze medievali: dinamiche di appartenenza a un corpo comunitario, a cura di S. Menzinger, Roma 2017, pp. 177-194.

G. Milani, Sulle relazioni politiche e ideologiche tra Carlo I d'Angiò e i comuni italiani. Una nota, in Construction et circulation des modèles et des pratiques politiques (France et Italie, XIII $-X V I^{e}$ siècle), a cura di I. Taddei, A. Lemonde, Roma 2014, pp. 115-127.

G. Milani, A. Montefusco, Prescindendo dai versi di Dante? Un percorso negli studi tra testi, biografia e documenti, in Dante attraverso i documenti. I. Famiglia e patrimonio (secolo XII-1300 circa), a cura di G. Milani, A. Montefusco, in «Reti Medievali. Rivista», 15/2 (2014): https://doi.org/10.6092/1593-2214/429.

N. Mineo, Mondo classico e città terrena in Dante, in Mineo, Dante: un sogno di armonia terrena, Torino-Catania 2005, vol. I, pp. 53-85.

J.-M. Moeglin, Henri VII: «l'homme qui voulait être empereur», in «Reti Medievali Rivista», 15/1 (2014): https://doi.org/10.6092/1593-2214/423.

G. Mollat, Les papes d'Avignon (1305-1378), Paris $1965^{10}$.

T. E. Mommsen, Italienische Analekten zur Reichsgeschichte des 14. Jahrhunderts, Stuttgart 1952.

A. Montefusco, Ancora su epistole dantesche e dictamen: osservazioni sulla salutatio dell'epistola VII e dintorni, in Sulle tracce del Dante minore. Prospettive di ricerca per lo studio delle fonti dantesche II, a cura di T. Persico, M. Sirtori e R. Viel, Bergamo 2019, pp. 17-30.

A. Montefusco, Dall'Università di Parigi a frate Alberto. Immaginario antimendicante ed ecclesiologia vernacolare in Giovanni Boccaccio, in «Studi sul Boccaccio», 43 (2015), pp. 177-232.

A. Montefusco, Epistole, in Dante, a cura di R. Rea, J. Steinberg, Roma 2020, pp. 123-144.

A. Montefusco, Epistole a c. di M. Baglio, in Su Dante Alighieri, Le opere, V, a c. di M. Baglio, L. Azzetta, M. Petoletti e M. Rinaldi, Roma, Salerno, 2016: Atti della tavola rotonda tenutasi a Venezia, 19-21 ottobre 2016, nell'ambito del convegno «Dante attraverso i documenti III. Contesti culturali e storici delle epistole dantesche», in «L'Alighieri», n.s. 50 (2017), pp. 125-132.

A. Montefusco, Essere notaio episcopale. Appunti sulla cultura di Francesco da Barberino, in Francesco da Barberino al crocevia.Culture, società, bilinguismo, a cura di

A. Montefusco, Berlin 2020, c.d.s.

A. Montefusco, La linea Guittone-Monte e la nuova parola poetica, in «Reti medievali rivista», 18/1 (2017), pp. 219-270: https://doi.org/10.6092/1593-2214/5097. 
A. Montefusco, Le "Epistole" di Dante: un approccio al corpus, in «Critica al testo», 14/1 (2011), pp. 401-457.

A. Montefusco, Petri de Vinea "Vehementi nimium commotus dolore": la restituzione del testo tra storia e filologia, in "La parola del testo», 11/2 (2007), pp. 299-365.

A. Montefusco, Pier della Vigna e la sua eredità: ars dictaminis, poesia, diritto $e$ distribuzione sociale dei saperi nella corte siciliana, in Poesia e diritto nel Due e Trecento italiano, a cura di F. Meier, Ravenna 2019, pp. 31-52.

A. Montefusco, S. Bischetti, Prime osservazioni su ars dictaminis, cultura volgare $e$ distribuzione dei saperi nella Toscana medievale, in «Carte Romanze», 6/1 (2018), pp. 163-240.

C. M. Monti, La "Genealogia" e il "De montibus": due parti di un unico progetto, in "Studi sul Boccaccio», 44 (2016), pp. 327-366.

C. M. Monti, Una raccolta di "exempla epistolarum". I. Lettere e carmi di Francesco da Fiano, in «Italia medioevale e umanistica», 27 (1984), pp. 121-160.

G. M. Monti, Sul dominio di Roberto a Firenze e a Genova, in Da Carlo I a Roberto d'Angiò. Ricerche e documenti, Trani 1936, pp. 161-179.

E. Moore, Studies in Dante, Oxford 1896.

E. Moore, The "Battifolle" Letters Sometimes Attributed to Dante, in «The Modern Language Review», vol. 9/2 (1914), pp. 173-189.

E. Moore, Two proposed emendations in Dante's Epistola VI, $\S 6$ (1910), in E. Moore, Studies in Dante. Fourth Series. Textual criticism of the "Convivio" and miscellaneous essays, Oxford 1917, pp. 280-283.

S. Morelli, Introduzione. Periferie finanziarie angioine: un sistema integrato?, in Périphéries financières angevines. Institutions et pratiques de l'administration de territoires composites (XIII $-X V^{e}$ siècle), a cura di S. Morelli, Roma 2018, pp. 1-18.

R. Morghen, Dante profeta. Tra la storia e l'eterno, Milano 1989.

R. Morghen, Le lettere politiche di Dante. Testimonianza della sua vita in esilio, in Dante profeta. Tra la storia e l'eterno, Milano 1989, pp. 89-107.

«Moribus antiquis sibi me fecere poetam». Albertino Mussato nel VII centenario dell'incoronazione poetica (Padova 1315-2015), a cura di R. Modonutti, E. Zucchi, Firenze 2017.

L. Mosiici, Ricerche sulla cancelleria di Castruccio Castracani, in «Annali della scuola speciale per archivisti e bibliotecari dell'Università di Roma», 7 (1967), pp. 1-86.

M. Motter, Il notaio Bongiovanni di Bonandrea e il suo protocollo, in Il "quaternus rogacionum" del notaio Bongiovanni di Bonandrea (1308-1320), a cura di D. Rando, M. Motter, Bologna 1997, pp. 29-67.

A. Moussatou, Oi ypotheseis tōn tragōdiōn tou Seneka, apospasmata agnōstou ypomnēmatos, stis tragōdies tou Seneka, kritikē ekdosē me eisagōgē kai paratērēseis A. C. Megas (= A. Mussati Argumenta tragoediarum Senecae, commentarii in L. A. Senecae tragoedias, fragmenta nuper reperta, cum praefatione, apparatu critico, scholiis edidit A. C. Megas), Thessalonikē 1969.

B. Munk Olsen, L'étude des auteurs classiques latins aux XI et XII ${ }^{e}$ siècles, I. Catalogue des manuscrits classiques latins copiés du IXe au XII e siècle. Apicius-Juvénal, Paris 1982,

G. Murano, Donne, sante e madonne (da Matilde di Canossa ad Artemisia Gentileschi), Imola 2018.

G. Murano, «Ò scritte di mia mano in su l'Isola della Rocca». Alfabetizzazione e cultura di Caterina da Siena, in «Reti Medievali Rivista», 18/1 (2017), pp. 139-176: https://doi.org/ 10.6092/1593-2214/5081. 
M. Musa, Advent at the Gates, Bloomington 1974.

J. N. Najemy, Storia di Firenze, 1200-1575, Torino 2014.

B. Nardi, Dante profeta, in B. Nardi, Dante e la cultura medievale, nuova ediz. a cura di

P. Mazzantini, introd. di T. Gregory, Roma-Bari 1983, pp. 265-326.

R. Nelli, Una corte feudale itinerante. I conti Guidi al cospetto dell'imperatore, in «Erba d'Arno», 63 (1996), pp. 51-59.

M. G. Nico Ottaviani, «Me son missa a scriver questa letera ...». Lettere e altre scritture femminili tra Umbria, Toscana e Marche nei secoli XV-XVI, Napoli 2006.

Il notariato a Perugia. Catalogo della Mostra documentaria e iconografica per il XVI Congresso nazionale del notariato (Perugia, maggio-luglio 1967), a cura di R. Abbondanza, Roma 1973.

Il notariato nel Casentino nel Medioevo. Cultura, prassi, carriere, a cura di A. Barlucchi, Firenze 2016.

F. Novati, La giovinezza di Coluccio Salutati (1331-1353). Saggio di un libro sopra la vita, le opere, i tempi di Coluccio Salutati, Torino 1888.

F. Novati, recensione a Zippel, Nicolò Niccoli, in «Giornale Storico della Letteratura Italiana», 17 (1891), pp. 114-117.

F. Novati, Le epistole. Conferenza letta nella sala di Dante in Orsanmichele, Firenze 1905 (poi in F. Novati, Freschi e minii del Dugento, Milano 1908, pp. 329-361).

F. Novati, L'epistola di Dante a Moroello Malaspina, in Dante e la Lunigiana, Milano 1909, pp. 505-542.

A. Olivieri, Serie dei consoli del comune di Genova, in «Atti della Società ligure di Storia Patria», 1 (1858), pp. 157-626.

L. Onder, Antico, in ED, 1.

E. Orioli, Documenti bolognesi sulla fazione dei Bianchi, in «Atti e memorie della R. Deputazione di Storia Patria per le Provincie di Romagna», s. III, XIV, 1896, pp. 1-15.

G. Orlandi, Le statistiche sulle clausole della prosa. Problemi e proposte, in «Filologia mediolatina», 5 (1998), pp. 1-35.

G. Orlandi, Recensione a T. Janson, Prose Rhythm in Medieval Latin from the 9th to the 13th Century, in «Studi Medievali», s. III, 89 (1978), pp. 701-718.

M. Orlandi, Una valle dantesca: il Casentino nella vita e nelle opere di Dante Alighieri, Scandicci 2002.

G. Padoan, La pubblicazione casentinese della prima dell'“Inferno", in Il lungo cammino del "poema sacro". Studi danteschi, Firenze 1993, pp. 39-56.

G. Padoan, Tra Dante e Mussato. I. Tonalità dantesche nell'«Historia Augusta» di Albertino Mussato, in «Quaderni veneti», 24 (1966), pp. 27-45.

G. Padoan, recensione ad A. Rossi, "Dossier" di un'attribuzione. Dieci anni dopo, in «Paragone», n.s. 36 (1968), pp. 61-125, in «Studi sul Boccaccio», 5 (1969), pp. 365-368.

A. Padovani, Santa Maria in Regola nel medioevo, in L'abbazia benedettina di Santa Maria in Regola. Quindici secoli di storia imolese, I, (Studi e ricerche), a cura di A. Ferri, M. Giberti, C. Pedrini, O. Orsi, Imola 2010, pp. 5-188.

Padovani, Dall'alba al crepuscolo del commento. Giovanni da Imola (1375 ca.-1436) e la giurisprudenza del suo tempo, Frankfurt am Main 2017.

F. Palermo, I Manoscritti Palatini di Firenze, Firenze 1868.

M. Palma, L'autografo di Dante, intervento alla Tavola rotonda Statuto e stato della catalogazione dei manoscritti in Italia e in Europa, in Catalogazione, storia della scrittura, storia del libro. I manoscritti datati d'Italia vent'anni dopo. Atti del convegno 
internazionale di studi (Cesena, Biblioteca Malatestiana, 4-5 dicembre 2014), c.d.s., leggibile su http://www.let.unicas.it/dida/links/didattica/palma/testi/palmaz1.htm.

G. Pampaloni, Bianchi e neri, in Enciclopedia Dantesca, Roma 1970-1978.

G. Pampaloni, I primi anni dell'esilio di Dante, in Conferenze aretine 1965, Arezzo-Bibbiena 1966, pp. 133-147.

E. Panella, Dal bene comune al bene del comune. I trattati politici di Remigio de' Girolami

(†1319) nella Firenze dei bianchi-neri, in «Memorie domenicane», 16 (1985), pp. 1-198.

E. Panella, Nuova cronologia remigiana, in «Archivum fratrum praedicatorum», 60 (1990), pp. 145-311.

E. Panella, Per lo studio di fra Remigio de’ Girolami (†1319), in «Memorie domenicane», 10 (1979), pp. 1-313.

E. Panella, Priori di Santa Maria Novella di Firenze, 1221-1325, in «Memorie domenicane», 17 (1986), pp. 253-284.

E. Panella, Remi de' Girolami, in Dictionnaire de spiritualité, t. XIII, Paris 1987, pp. 343-347.

E. Panella, Remigiana: note biografiche e filologiche, in «Memorie domenicane», 13 (1982), pp. 366-421.

E. Panella, Un'introduzione alla filosofia in uno "studium" dei frati Predicatori del XIII secolo, in «Memorie domenicane», 12 (1981), pp. 27-126.

A. Paravicini Bagliani, Clemente V, in Enciclopedia dei papi, Roma 2000, vol. II, pp. 501-12.

S. Parent, Dans les abysses de l'infidélité: les procès contre les ennemis de l'église en Italie au temps de Jean XXII (1316-1334), Rome 2014.

S. Parent, Publication et publicité des procès à l'époque de Jean XXII (1316-1334): l'example des seigneurs gibelins italiens et de Louis de Bavière, in «Mélanges de l'École Française de Rome Moyen Âge», 119/1 (2007), pp. 93-134.

E. G. Parodi, La data della composizione e le teorie politiche dell'Inferno e del Purgatorio. Secondo articolo, in Poesia e Storia nella "Divina Commedia", a cura di G. Folena, P. V. Mengaldo, Vicenza 1965, pp. 263-324.

E. G. Parodi, Intorno al testo delle epistole di Dante e al "cursus", in "Bullettino della Società dantesca italiana», n.s. 19 (1912), pp. 249-275 e 22 (1915), pp. 137-144 (poi in E. G. Parodi, Lingua e letteratura. Studi di teoria linguistica e di storia dell'italiano antico, a cura di G. Folena, con un saggio introduttivo di A. Schiaffini, II, Venezia 1957, pp. 399442).

P. Partner, The lands of St Peter: the papal state in the Middle Ages and the early Renaissance, London 1972.

G. Pascoli, Mirabile visione, in G. Pascoli, Prose. II. Scritti danteschi, a cura di A. Vicinelli, Milano 1971, pp. 1071-1089.

U. Pasqui, Documenti per la storia della città di Arezzo nel Medio Evo. II. Codice diplomatico (anno 1180-1337), Firenze 1920.

E. Pasquini, Cupidigia, in ED, 2.

E. Pasquini, Cupidità, in ED, 2.

E. Pasquini, Fra Due e Quattrocento. Cronotopi letterari in Italia, Milano 2013.

E. Pasquini, Intersezioni fra prosa e poesia nelle Lettere di Guittone, in Guittone d'Arezzo nel settimo centenario della morte. Atti del Convegno Internazionale di Arezzo, a cura di M. Picone, Firenze 1995, pp. 177-204.

E. Pasquini, Un crocevia dell'esilio: la canzone "montanina" e l'epistola a Moroello Malaspina, in Studi dedicati a Gennaro Barbarisi, a cura di C. Berra, Milano 2007, pp. 13-29.

A. Passerin d'Entrèves, Dante politico, in Dante politico e altri saggi, Torino 1955, pp. 37-128.

M. Pastore Stocchi, Epistole, in Enciclopedia Dantesca, Roma 1970-1978. 
M. Pastore Stocchi, Petrarca e Dante, in «Rivista di studi danteschi», 4 (2004), pp. 184-204.

E. Pasquini, Vita di Dante. I giorni e le Opere, Milano 2006.

G. Pedullà, Machiavelli in tumulto. Conquista, cittadinanza e conflitto nei «Discorsi sopra la prima deca di Tito Livio», Roma 2011.

P. Pellegrini, Dante: biografia, ideologia e politica editoriale (1965-2015), in "Quando soffia Borea". Dante e la Scandinavia (1265-2015). Atti dell'VIII seminario di letteratura italiana (Helsinki, 26 ottobre 2015), a cura di E. Garavelli, Helsinki 2016, pp. 9-54.

P. Pellegrini, Dante da Forlí a Verona, in P. Pellegrini, Dante tra Romagna e Lombardia, Padova 2016, pp. 39-61.

P. Pellegrini, Dante tra Romagna e Lombardia. Studi di linguistica e di filologia italiana, Padova 2016.

P. Pellegrini, I primi passi dell'esilio dantesco, in Dante a Verona 2015-2021, a cura di E. Ferrarini, P. Pellegrini, S. Pregnolato, Ravenna 2018, pp. 25-43.

P. Pellegrini, Lo stilista nascosto di Cangrande, in «Alias/Il Manifesto», 16 settembre 2018.

P. Pellegrini, La quattordicesima epistola di Dante Alighieri. Primi appunti per una attribuzione, in «Studi di erudizione e filologia italiana», 7, 2018, pp. 5-20.

K. Pennington, The Prince and the Law, 1200-1600: Sovereignty and Rights in the Western Legal Tradition, Berkeley 1993.

L. Pertile, Dante looks forward and back: political allegory in the Epistles, in «Dante Studies», 115 (1997), pp. 1-17.

M. Petoletti, Boccaccio editore delle egloghe e delle epistole di Dante, in Boccaccio editore e interprete di Dante. Atti del Convegno internazionale (Roma, 28-30 ottobre 2013), a cura di L. Azzetta, A. Mazzucchi, Roma 2014, pp. 159-183.

M. Petoletti, Epistole, in Boccaccio autore e copista, a cura di T. De Robertis, C. M. Monti et al., Firenze 2013, pp. 233-241.

M. Petoletti, Gli zibaldoni di Giovanni Boccaccio, in Boccaccio autore e copista, a cura di M. Petoletti, S. Zamponi, Firenze 2013, pp. 291-326.

M. Petoletti, Il Boccaccio e la tradizione dei testi latini, in Boccaccio letterato. Atti del Convegno internazionale (Firenze-Certaldo, 10-12 ottobre 2013), a cura di M. Marchiaro, S. Zamponi, Firenze 2015, pp. 105-121.

M. Petoletti, Le "Egloghe" di Dante: problemi e proposte testuali, in Dante e la sua eredità a Ravenna nel Trecento, a cura di M. Petoletti, Ravenna 2015, pp. 11-39.

M. Petoletti, Milano e i suoi monumenti: La descrizione trecentesca del cronista Benzo d'Alessandria, Alessandria 2004.

M. Petoletti, S. Zamponi, Gli Zibaldoni, in Boccaccio autore e copista, a cura di T. De Robertis, C. M. Monti, M. Petoletti, G. Tanturli, S. Zamponi, Firenze 2013, pp. 289-326.

G. Petralia, Fiscalità, politica e dominio nella Toscana fiorentina, in Lo stato territoriale fiorentino (secoli XIV-XV). Ricerche, linguaggi, confronti. Seminario internazionale di studi (San Miniato, 7-8 giugno 1996, a cura di W. J. Connel, A. Zorzi, Pisa 2002, pp. 161-187.

G. Petralia, I Toscani nel mezzogiorno medievale: genesi ed evoluzione trecentesca di una relazione di lungo periodo, in La Toscana nel secolo XIV. Caratteri di una civiltà regionale, a cura di S. Gensini, Pisa 1988, pp. 287-301.

G. Petrocchi, Intorno alla pubblicazione dell'Inferno e del Purgatorio, in Itinerari danteschi, a cura di C. Ossola, Milano 1994, pp. 63-87.

G. Petrocchi, Vita di Dante, Bari-Roma 1984.

A. Petrucci, Scrittura, alfabetismo ed educazione grafica nella Roma del primo Cinquecento. Da un libretto di conti di Maddalena pizzicarola in Trastevere, in "Scrittura e civiltà», 2 (1978), pp. 163-207. 
A. Petrucci, Scrivere per gli altri, in «Scrittura e civiltà», 13 (1989), pp. 475-487; poi anche in Istruzione, alfabetismo, scrittura. Saggi di storia dell'alfabetizzazione in Italia (sec. XV$X I X)$, a cura di A. Bartoli Langeli, X. Toscani, Milano 1991, pp. 61-74.

A. Petrucci, Storia e geografia delle culture scritte (dal secolo XI al secolo XVIII), in Letteratura italiana. Storia e geografia, a cura di A. Asor Rosa. II/1-2. L'età moderna, Torino 1988, pp. 1193-1292 (ora in Petrucci, Letteratura italiana: una storia attraverso la scrittura, Roma 2017).

A. Pézard, «La rotta gonna». Gloses et corrections aux textes mineurs de Dante, FirenzeParis, 1967-1979.

A. Piacentini, Domenico Silvestri, con una nota sulla scrittura di I. Ceccherini, in Autografi dei letterati italiani. Le Origini e il Trecento, a cura di G. Brunetti, M. Fiorilla, M. Petoletti, Roma 2013, vol. I, pp. 289-299.

R. Piattoli, Alberti, Orso, in ED, 1.

R. Piattoli, Benincasa da Laterina, in ED, 1.

R. Piattoli, Codice diplomatico dantesco. Aggiunte, Aggiunta VII. Frate Bernardo Riccomanni destinatario dell'epistola di Dante «all'Amico Fiorentino», in «Archivio Storico Italiano», 127 (1969), pp. 85-108.

R. Piattoli, Scornigiani, Gano, in ED, 5.

A. M. Piazzoni, Concoregio, Rinaldo da, beato, in DBI, 27 (1982).

D. Piccini, Un amico del Petrarca: Sennuccio del Bene e le sue rime, Padova 2004.

Piendibeni, Francesco, in ED, 4.

V. Pini, La tradizione manoscritta di Guido Faba dal XIII al XV secolo, in Magistri Guidonis Fabe Rota nova: ex codice manuscripto oxoniensi New College 255 nunc primum prodit, a cura di A. Campbell, V. Pini, A. Saiani, Bologna 2000, pp. 251-452.

G. Pinto, Aspetti della guerra tra Firenze e Ludovico il Bavaro in alcune lettere della cancelleria fiorentina, in «Archivio Storico Italiano», 131 (1973), pp. 225-40.

R. Pinto, Gli anni e la poetica dell'esilio (1302-1307): periodizzazione, in «Tenzone», 16 (2015), pp. 31-70.

R. Pinto, La poetica dell'esilio e la tenzone con Cino, in «Tenzone. Revista de la Asociación Complutense de Dantología», 10 (2010), pp. 41-74.

P. Pirillo, La signoria dei conti Guidi tra dinamiche di lignaggio e poteri territoriali, in La lunga storia di una stirpe comitale. I conti Guidi tra Romagna e Toscana, Atti del Convegno (Poppi-Modigliana 2003), a cura di F. Canaccini, Firenze 2008, pp. 267-290.

S. Piron, Allégories et dissidences médiévales, in Allégorie et symboles. Voies de dissidence? De l'antiquité à la Renaissance, a cura di A. Rolet, Rennes 2012, pp. 243-68.

S. Piron, La parole prophétique, in Le pouvoir des mots au Moyen Âge, éds. N. Beriou, J. P. Boudet, I. Rosier Catach, Turnhout 2014, pp. 255-86.

E. Pispisa, Alberto I d'Asburgo, in ED, 1.

E. Pispisa, Margherita di Brabante, in ED, 3.

E. Pistelli, rec. a Toynbee, in «Bullettino della Società dantesca italiana», n.s. 22 (1917), pp. 58-65.

E. Pistelli, Dubbi e proposte sul testo delle Epistole, in «Studi Danteschi», 1 (1920), pp. 149155.

T. Plebani, Le scritture delle donne in Europa. Pratiche quotidiane e ambizioni letterarie (secoli XIII-XX), Roma 2019.

M. Plezia, Quattuor stili modernorum. Ein Kapitel mittellateinischer Stillehre, in Orbis Mediaevalis, Weimar 1970, pp. 192-210.

E. J. Polak, A textual study of Jacques de Dinant's «Summa dictaminis», Genève 1975. 
A. Poloni, Banchieri del re. La monarchia angioina e le compagnie toscane da Carlo I a Roberto, in Périphéries financières angevines. Institutions et pratiques de l'administration de territoires composites (XIII $-X V^{e}$ siècle), a cura di S. Morelli, Roma 2018, pp. 309-330.

A. Poloni, Ordelaffi, Scarpetta, in DBI, 79 (2013).

P. Pontari, Sulla dimora di Dante a Forli: Pellegrino Calvi, Benvenuto da Imola e Biondo Flavio, in «Studi danteschi», 80 (2015), pp. 183-241.

G. Post, Two Notes on Nationalism in the Middle Ages, in «Traditio», 9 (1953), pp. 281-320.

G. L. Potestà, Dante profeta e $i$ vaticini papali, in «Rivista di Storia del Cristianesimo», 1 (2004), pp. 67-88.

G. L. Potestà, La condanna del «libellus» trinitario di Gioacchino da Fiore: oggetto, ragioni, esiti, in The Fourth Lateran Council. Institutional Reform and Spiritual Renewal, Proceedings of the Conference, Rome 15-17 October 2015, eds. G. Melville, J. Helmrath, Affalterbach 2017, pp. 203-223.

G. L. Potestà, L'ultimo messia. Sovranità e profezia nel Medioevo, Bologna 2014.

W. Purcell, Transsumptio: A Rhetorical Doctrine of the Thirteenth Century, in «Rhetorica», 5 (1987), pp. 369-410.

A. E. Quaglio, La poesia realistica e la prosa del Duecento, Roma-Bari 1971.

D. Quaglioni, La "Monarchia", l'ideologia imperiale e la cancelleria di Enrico VII, in Enrico VII, Dante e Pisa a 700 anni dalla morte dell'imperatore e dalla Monarchia (1313-2013), a cura di G. Petralia, M. Santagata, Ravenna 2016.

D. E. Queller, The Office of Ambassador in the Middle Ages, Princeton 1967.

C. Rabel, Le "Sénèque des ducs". Un cadeau lombard pour Jean de Berry, in "Revue de l'Art», 135 (2002), pp. 7-22.

J. Rabiot, "Fatta fedelmente volgarizzare». Documents traduits et insérés dans la «Nuova cronica» de Giovanni Villani (Florence, XIVe siècle), in «Médiévales», 75 (2018), pp. 4966.

P. Racine, La signoria di Alberto Scotti, in Storia di Piacenza, II, Dal vescovo conte alla signoria (996-1313), Piacenza 1984, pp. 331-346.

E. Ragni, Brosse, Pierre de la (Pier de la Broccia), in Enciclopedia Dantesca, Roma 19701978.

F. Ragone, Giovanni Villani e i suoi continuatori. La scrittura delle cronache a Firenze nel Trecento, Roma 1998.

G. Ragonese, Federico (Federigo) Novello, in ED, 2.

M. Rainini, «Firmiter credimus». Premesse teologiche e obiettivi polemici della costituzione I del Concilio Lateranense IV, in Il Lateranense IV. Le ragioni di un concilio, Todi, 9-12 ottobre 2016, Spoleto 2017, pp. 111-156.

P. Rajna, Per il "cursus" medievale e per Dante, in «Studi di filologia italiana», 3 (1932), pp. 7-86.

D. Rando, Fonti trentine per Enrico di Metz fra Italia comunale e Mitteleuropa, in II “quaternus rogacionum" del notaio Bongiovanni di Bonandrea (1308-1320), a cura di D. Rando, M. Motter, Bologna 1997, pp. 7-27.

R. Rao, Signori di Popolo. Signoria cittadina e società comunale nell'Italia nord-occidentale 1275-1350, Milano 2011.

N. Rauty, I conti Guidi in Toscana, in Formazione e strutture dei ceti dominanti nel Medioevo: marchesi, conti e visconti nel regno italico (secc. IX-XII). Atti del II convegno (Pisa, 3-4 dicembre 1993), in «Nuovi studi storici», 39 (1996), pp. 241-64.

S. Raveggi, L'Italia dei guelfi e dei ghibellini, Milano 2009. 
S. Raveggi, M. Tarassi, D. Medici, P. Parenti, Ghibellini, Guelfi e popolo grasso. I detentori del potere politico a Firenze nella seconda metà del Dugento, Firenze 1978.

R. Rea, Cavalcanti e l'invenzione del lettore, in Les deux Guidi. Guinizzelli et Cavalcanti. Mourir d'aimer et autres ruptures, a cura di M. Gagliano, P. Guérin, R. Zanni, Paris 2016, pp. 157-70.

M. Reeves, The influence of prophecy in the later Middle Ages: a study in joachimism, Oxford 1969.

C. Revest, "Romam veni". L'humanisme à la curie de la fin du Grand Schisme, d'Innocent VII au concile de Constance (1404-1417), tesi di dottorato, rel. E. Crouzet-Pavan, J. C. Maire Vigueur, Université Paris-Sorbonne (Paris IV)-Università degli Studi di Firenze 2012.

C. Ricci, L'ultimo rifugio di Dante Alighieri, Milano 1891.

F. Ricciardelli, The Politics of Exclusion in Early Renaissance Florence, Turnhout 2007.

C. Ricottini Marsili-Libelli, Anton Francesco Doni scrittore e stampatore, Firenze 1963.

T. Ricklin, “more cuiusdam cioli et aliorum infamium". On Dante's Refusal to Return Home and How he Becam Florentine Again, in Images of Shame. Infamy, Defamation and the Ethics of oeconomia, Berlin 2016, pp. 141-168.

P. Riesenberg, Inalienability of Sovereignty in Medieval Political Thought, New York 1965.

S. Riezler, Vatikanische Akten zur deutschen Geschichte in der Zeit Kaiser Ludwigs des Bayern, Innsbruck 1891.

P. Rigo, Tempo liturgico nell'epistola dantesca ai Principi e ai Popoli d'Italia, in «Lettere Italiane», 32/2 (1980), pp. 222-231, poi confluito in Rigo, Memoria classica e memoria biblica in Dante, Firenze 1994, pp. 33-44.

P. Rigoli, L'esibizione del potere. Curie e feste scaligere nelle fonti cronistiche, in Gli Scaligeri 1277-1387. Saggi e schede raccolti in occasione della mostra storico-documentaria, a cura di G. M. Varanini, Verona 1988, pp. 149-156.

S. Rizzo, «La lingua nostra»: il latino di Dante, in Dante fra il settecentocinquantenario della nascita (2015) e il settecentenario della morte (2021). Atti delle Celebrazioni in Senato, del Forum e del Convegno internazionale di Roma (maggio-ottobre 2015), a cura di E. Malato, A. Mazzucchi, vol. II, Roma 2016, pp. 535-557.

S. Rizzo, Note sulla latinità di Dante, in «Italia medioevale e umanistica», 58 (2017), pp. 283-292.

D. M. Robathan, Boccaccio's accuracy as a scribe, in «Speculum», 13 (1938), pp. 458-460.

W. R. Robins, Antonio Pucci, guardiano degli Atti della Mercanzia, in «Studi e problemi di critica testuale», 61 (2000), pp. 29-70.

W. Robins, The Case of the Court Entertainer: Popular. Culture, Intertextual Dialogue, and the Early. Circulation of Boccaccio's Decameron, in «Speculum», 92 (2017), pp. 1-35.

A. Rodolfi, Cognitio obumbrata: lo statuto epistemologico della profezia nel secolo XIII, Firenze 2016.

E. Romanini, Boccaccio "auctoritas" nel commento di Francesco Piendibeni al "Bucolicum carmen" del Petrarca, in Intorno a Boccaccio / Boccaccio e dintorni. Atti del Seminario internazionale di studi (Certaldo Alta, Casa di Giovanni Boccaccio, 25 giugno 2014), a cura di G. Frosini, S. Zamponi, Firenze 2015, pp. 59-75.

E. Romanini, L'esegesi di Francesco Piendibeni al "Bucolicum carmen" del Petrarca (ms. Vat. Pal. lat. 1729). Edizione critica e commento. Egloghe I-IX e XI-XII (con una trascrizione dei “marginalia" all'egloga $X$ ), tesi di dottorato, rel. S. Fiaschi, H. Casanova-Robin, Università degli Studi di Macerata-Université Paris-Sorbonne (Paris IV) 2016.

E. Romanini, Francesco Piendibeni, in Autografi dei letterati italiani. Le Origini e il Trecento, a cura di G. Brunetti, M. Fiorilla, M. Petoletti, vol. II, c.d.s. 
E. Romanini, Verso l'edizione critica del commento di Francesco Piendibeni al "Bucolicum carmen", saggio derivato dalla comunicazione presentata in Laureatus in Urbe.

Seminario annuale di studi petrarcheschi (Roma, Università degli Studi Roma Tre, 22-23 maggio 2017), c.d.s.

E. Romanini, Francesco Piendibeni lettore del Boccaccio: le postille alla "Genealogia" del codice Vat. lat. 2940, saggio derivato dalla comunicazione presentata in Intorno a Boccaccio / Boccaccio e dintorni. Seminario internazionale, V edizione (Certaldo Alta, Casa di Giovanni Boccaccio, 6-7 settembre 2018), c.d.s.

A. Roncaglia, Il canto VI del Purgatorio, in «La rassegna della letteratura italiana», 60 (1956), pp. 409-426.

M. Ronzani, La chiesa cittadina pisana tra Due e Trecento, in Genova, Pisa e il Mediterraneo tra Due e Trecento. Per il VII centenario della battaglia della Meloria, Genova 1984, pp. 283-347.

I. Rosier-Catach, La parole efficace. Signe, rituel, sacré, Paris 2004.

G. Rossetti, Sullo spirito antipapale che produsse la Riforma, e sulla segreta influenza ch'esercitò nella letteratura d'Europa, e specialmente d'Italia, come risulta da molti suoi classici, massime da Dante, Petrarca, Boccaccio, London 1832.

L. Rossetto, Per il testo critico delle Epistole dantesche: l'uso del «cursus», in M. Bordin, P. Fusco, L. Rossetto, Tre studi danteschi, Roma 1993, pp. 63-131.

A. Rossi, Ingresso, in «Poliorama. Semestrale di analisi filologiche e ricerche interdisciplinari», 3 (1984), pp. 1-2.

A. Rossi, Da Dante a Leonardo. Un percorso di originali, Firenze 1999.

M. Ryan, Bartolus of Sassoferrato and Free Cities: the Alexander Prize Lecture, in "Transactions of the Royal Historical Society», 10 (2000), pp. 65-89.

L. Ruggio, Repertorio bibliografico del teatro umanistico, Firenze 2011.

V. Russo, Dante "exul immeritus". Variazioni compositive sul/dal tema, in «Esperienze letterarie», 17/2 (1992), pp. 3-16.

V. Russo, Impero e stato di diritto. Studio su «Monarchia» ed «Epistole» politiche di Dante, Napoli 1987.

E. Ruth, Studien über Dante Allighieri: ein Beitrag zum Verständriss der göttlichen Komödie, Tübingen 1853.

S. Saffiotti Bernardi, Malaspina, Moroello, in ED, 3.

S. Saffiotti Bernardi, Tarlati, Guccio, in ED, 5.

A. Saiani, La figura di Guido Faba nel prologo autobiografico della Rota nova. Una rilettura, in Magistri Guidonis Fabe Rota nova: ex codice manuscripto oxoniensi New College 255 nunc primum prodit, a cura di A. Campbell, V. Pini, A. Saiani, Bologna 2000, pp. 469-508.

V. Salaverty y Rosa, Cerdeña y la expansión mediterránea de la Corona de Aragón (12971314), Madrid 1956.

E. Salvatori, Malaspina, Moroello, in DBI, 67 (2006).

A.-E.-K. Salza, Del carteggio di Alessandro Torri. Letture scelte sugli autografi e postillate, Pisa 1897.

C. Samaran, R. Marichal, Catalogue des manuscrits en écriture latine portant des indications de date, de lieu ou de copiste, Paris 1974, vol. III/1-2. Bibliothèque Nationale, Fonds Latin (n ${ }^{\text {os }} 8001$ à 18613).

M. Santagata, Dante. Il romanzo della sua Vita, Milano 2012.

M. Santagata, Il racconto della Commedia. Guida al poema di Dante, Milano 2017.

F. Santi, Arnau de Vilanova: l'obra espiritual, Valencia 1987.

A. Sapori, La crisi delle compagnie mercantili dei Bardi e dei Peruzzi, Firenze 1926. 
G. Sasso, Dante, l'imperatore e Aristotele, Roma 2002.

G. Savino, L'autografo virtuale della Commedia, in "Per correr miglior acque ...» Bilanci e prospettive degli studi danteschi alle soglie del nuovo millennio. Atti del convegno internazionale (Verona-Ravenna, 25-29 ottobre 1999), Roma 2001, pp. 1099-1110.

G. Scarpelli, Scultura giacente di vescovo, in Scultura a Montepulciano dal XIII al XX secolo, introduzione storica di G. Greco, testi di G. Scarpelli, A. Sigillo et al., schede di I. larrapino, A. Marzuoli et al., Montepulciano 2003, pp. 41-42.

G. A. Scartazzini, Dante in Germania, Napoli-Milano-Pisa 1881.

G. A. Scartazzini, Dantologia: vita e opere di Dante Alighieri, Milano 1894.

G. A. Scartazzini, Enciclopedia dantesca, continuata dal prof. A. Fiammazzo, Milano 1905.

B. Scavizzi, Abbiamo un autografo di Arnau de Vilanova?, in «Arxiu de Textos Catalans Antics», 30 (2011), pp. 413-38.

L. Scavo Lombardo, Buona fede (diritto canonico), in Enciclopedia del diritto, Milano 1960, vol. III, pp. 368-370.

H. M. Schaller, Ein Manifest des Grafen Guido von Montefeltro nach der Schlacht von Forlì (1. Mai 1282), in Storiografia e storia. Studi in onore di Eugenio Duprè Theseider, Roma 1973, pp. 669-87 (rist. in H. M. Schaller, Stauferzeit. Ausgewählte Aufsätze, Hannover 1993, pp. 423-442).

H. M. Schaller, Handschriftenverzeichnis zur Briefsammlung des Petrus de Vinea, Hannover 2002. H. M. Schaller, L'epistolario di Pier della Vigna, in Politica e cultura nell'Italia di Federico II, a cura di S. Gensini, Pisa 1986, pp. 95-111 (rist. in H. M. Schaller, Stauferzeit. Ausgewählte Aufsätze, Hannover 1993, pp. 463-478).

H. M. Schaller, Stauferzeit. Ausgewählte Aufsätze, Hannover 1993.

H. M. Schaller, Studien zur Briefsammlung des Kardinals Thomas von Capua, in «Deutsches Archiv für Erforschung des Mittelalters», 21 (1965), pp. 371-518.

H. M. Schaller, Zur Entstehung der sogenannten Briefsammlung des Petrus de Vinea, in «Deutsches Archiv für Erforschung des Mittelalters», 12 (1956), pp. 114-159 (rist. in H. M. Schaller, Stauferzeit. Ausgewählte Aufsätze, Hannover 1993, pp. 225-270).

H. M. Schaller, B. Vogel, Hanschriftenverzeichnis zur Briefsammlung des Petrus de Vinea, Hannover 2002.

H. M. Schaller, K. Stobener, M. Thumser, Handschriftenverzeichnis zur Briefsammlung des Thomas von Capua, Wiesbaden 2017.

G. P. G. Scharf, Potere e società ad Arezzo nel XIII secolo (1214-1312), Spoleto 2013.

P. Scheffer-Boichorst, Aus Dante's Verbannung. Literarhistorische Studien, Strassburg 1882.

M. Scherillo, Ciacco e Dante uomini di corte, in «Emporium. Rivista mensile illustrata d'Arte e di Coltura», 314 (1921), pp. 58-74.

A. Schiaffini, Gli stili prosastici e la prosa rimata nel Medioevo latino, in A. Schiaffini Tradizione e poesia nella prosa d'arte italiana dalla latinità medievale a $G$. Boccaccio, Roma 1943, p. 11-24.

F. Schneider, Kaiser Heinrich VII. Dantes Kaiser, Stuttgart-Berlin 1943.

F. Schneider, Untersuchungen zur italienischen Verfassungsgeschichte. Anhang II. Analekten zum Römerzug Heinrichs VII., in «Quellen und Forschungen aus italienischen Archiven und Bibliotheken», 18 (1926), pp. 256-266.

F. Scolari, Intorno alle epistole latine di Dante Allighieri, giusta l'edizione fattasene in Breslavia nel 1827, ed ultimamente in Livorno nel 1843, lettera critica, Venezia 1844.

J.A. Scott, Dante ha rivisto il testo dell'Inferno nel 1314?, in «Studi Danteschi», 76 (2011), pp. 115-128.

C. Segre, Lingua, stile e società, Milano 1963. 
M. Serck, Berthold von Neuffen im Dienste Ludwigs des Bayern, Berlin 1936.

E. Sestan, Dante e i conti Guidi, in Conferenze aretine 1965, Arezzo-Bibbiena 1966, pp. 101131.

G. Sforza, Castruccio Castracani degli Antelminelli e gli altri Lucchesi di parte bianca in esilio (1300-1314), in «Memorie della R. Accademia di Scienze di Torino», s. II, 42 (1891), pp. 47-104.

P. Silva, Giacomo Il d'Aragona e la Toscana (1307-1309), in «Archivio Storico Italiano», 71 (1913), pp. 23-57.

D. Silvestri, The Latin Poetry, edited with an introduction and notes by R. C. Jensen, München 1973.

L. Simeoni, Le Signorie (1313-1559), Milano 1950.

M. Simonetti, Introduzione all'edizione critica dell'Apologia di Rufino contro s. Girolamo, in «Maia», n.s. IV/8 (1956), pp. 294-321.

I. Sluiter, Obscurity, in Canonical texts and scholarly practices. A global comparative approach, a cura di A. Grafton, G. Most, Cambridge 2016, pp. 34-51.

A. Solerti, Le Vite di Dante, Petrarca e Boccaccio scritte fino al secolo decimosesto, Milano 1904.

A. Solmi, L'Italia nel pensiero politico di Dante, in Il pensiero politico di Dante. Studi storici, Firenze 1922, pp. 193-218.

F. Somaini, Dante e il quadro politico italiano. Lettura di Purgatorio VI, in Lectura Dantis Lupiensis. Vol. 2 2013, a cura di V. Marucci, V. Puccetti, Ravenna 2014, pp. 7-99.

F. Somaini, Henri VII et le cadre italien : la tentative de relancer le Regnum Italicum. Quelques réflexions préliminaires, in Europäische Governance in Spätmittelalter. Heinrich VII. von Luxembourg und die grossen Dynastien in Europas Gouvernance européenne au bas moyen âge. Henri VII de Luxembourg et l'Europe des grandes dynasties. Actes des $15^{\text {es }}$ journées lotharingiennes. 14-15 octobre 2008. Université de Luxembourg, a cura di M. Pauly, Luxembourg 2010, pp. 397-428.

F. Somaini, La crisi delle città-stato, in Geografie politiche italiane tra Medioevo e Rinascimento, Milano 2012, pp. 13-50.

R. W. Southern, Towards an edition of Peter of Blois's letter-collection, in «English Historical Review», 110 (1995), pp. 925-937.

C. P. E. Springer, The Manuscripts of Sedulius. A Provisional Handlist, Philadelphia 1995. Lo stato territoriale fiorentino (secoli XIV-XV). Ricerche, linguaggi, confronti, a cura di A. Zorzi, W. J. Connell, Pisa 2002.

A. Stefanin, Pietro Alighieri rimatore, in «Studi Danteschi», 66 (2001), pp. 63-146.

J. Steinberg, Accounting for Dante. Urban Readers and Writers in Late Medieval Italy, Notre Dame 2007 (tr. It. J. Steinberg, Dante e il suo pubblico. Copisti, scrittori e lettori nell'Italia comunale, Roma 2018).

J. Steinberg, Dante and the Limits of the Law, Chicago 2013.

F. Stella, I manuali di epistolografia delle scuole aretine fra XII e XIII secolo: documenti manoscritti di una tradizione inesplorata, in La produzione scritta tecnica e scientifica nel Medioevo: libro e documento tra scuole e professioni, a cura di G. De Gregorio, Spoleto 2012, pp. 1-35.

F. Stella, Chi scrive le mie lettere? La funzione-autore e l'eterografia nei modelli epistolari latini del XII secolo, in E. D'Angelo, J. M. Ziolkowski (eds.), Auctor et Auctoritas, pp. 1071-1096.

H. Stieglitz, Erinnerungen an Rom und den Kirchenstaat im ersten Jahre seiner Verjüngung, Leipzig 1848. 
C. Storti Storchi, Appunti in tema di «Potestats Condendi Statuta», in Scritti sugli statuti lombardi, Milano 2007, pp. 115-138.

P. T. Struck, Birth of the symbol. Ancient readers at the limits of their texts, Princeton 2004.

Su Dante Alighieri, Le opere, V, a c. di M. Baglio, L. Azzetta, M. Petoletti e M. Rinaldi, Roma, Salerno, 2016. Atti della tavola rotonda tenutasi a Venezia, 19-21 ottobre 2016, nell'ambito del convegno «Dante attraverso i documenti III. Contesti culturali e storici delle epistole dantesche», in «L'Alighieri», 50 (2017), pp. 125-151.

B. H. Sumner, Dante and the Regnum Italicum, in «Medium Aevum», 1 (1932), pp. 2-23.

C. Sutter, Aus Leben und Schriften des Magisters Boncompagno, Freiburg i. B. 1894.

G. Tabacco, Egemonie sociali e strutture del potere nel medioevo italiano, Torino 1979.

G. Tabacco, La casa di Francia nell'azione politica di papa Giovanni XXII, Roma 1953.

F. Tamburini, Note diplomatiche intorno a suppliche e lettere di Penitenzieria (sec. XIV-XV), in «Archivum Historiae Pontificiae», 11 (1973), pp. 149-208.

G. Tanturli, Un nodo cronologico e tematico: l'invectiva in Florentinos d'Antonio Loschi, la risposta di Coluccio Salutati e la Laudatio florentine urbis di Leonardo Bruni, in L'Humanisme italien de la Renaissance et l'Europe, a cura di G. Tanturli, T. Picquet, L. Faggion, P. Gandoulphe, Aix en Provence 2010, pp. 109-119.

M. Tarassi, Della Tosa, Baschiera, in DBI, 37 (1989).

M. Tavoni, Convivio e De vulgari eloquentia: Dante esule, filosofo laico e teorico del volgare, in «Nuova rivista di letteratura italiana», 17/1 (2014), pp. 11-54.

M. Tavoni, «De vulgari eloquentia»: luoghi critici, storia della tradizione, idee linguistiche, in Storia della lingua italiana e filologia. Atti del VII Convegno internazionale dell'ASLI (Associazione per la Storia della Lingua Italiana), Pisa-Firenze, 18-20 dicembre 2008, a cura di C. Ciociola, Firenze 2010, pp. 47-72.

M. Tavoni, La cosiddetta battaglia della Lastra e la biografia politica di Dante, in «Nuova rivista di letteratura italiana», 17/2 (2014), pp. 51-87.

M. Tavoni, L'idea imperiale nel De vulgari eloquentia, in Enrico VII, Dante e Pisa. A 700 anni dalla morte dell'Imperatore e dalla "Monarchia" (1313-2013). Atti del Convegno internazionale (Pisa-San Miniato, 24-26 ottobre 2013), a cura di G. Petralia, M. Santagata, Ravenna 2016, pp. 215-233.

M. Tavoni, Qualche idea su Dante, Bologna 2015.

M. Tavoni, Un paesaggio memoriale ricorrente nella Divina Commedia: i fiumi che decorrono dal versante destro e sinistro dell'Appennino, in «Deutsches Dante-Jahrbuch», 92/1 (2017), pp. 50-65.

M. Tavoni, E. Chersoni, Ipotesi d'interpretazione della «supprema constructio» (De vulgari eloquentia, in «Studi di grammatica italiani», 21-22 (2012-2013), pp. 131-158.

P. Terenzi, Gli Angiò in Italia centrale. Potere e relazioni politiche in Toscana e nelle terre della Chiesa (1263-1335), Roma 2019.

C. Thiry, La plainte funèbre, Turnhout 1978.

H. Thomas, Ludwig der Bayer (1282-1347): Kaiser und Ketzer, Regensburg 1993.

D. Thomson, J. J. Murphy, Dictamen as a Developed Genre: the Fourteenth Century "Brevis doctrina dictaminis" of Ventura da Bergamo, in «Studi medievali» S. III, 23 (1982), pp. 361-386.

M. Thumser, Zur Überlieferungsgeschichte der Briefe Papst Clemens' IV (1265-1268), in «Deutsches Archiv für Erforschung des Mittelalters», 51 (1995), pp. 115-68.

M. Thumser, Les grandes collections de lettres de la curie pontificale au XIII ${ }^{e}$ siècle. Naissance, structure, édition, in Le dictamen dans tous ses états. Perspectives de 
recherche sur la théorie et la pratique de l'ars dictaminis (XIe-XVe siècles), éds.

B. Grévin, A.-M. Turcan-Verkerk, Turnhout 2015, pp. 209-241.

M. Thumser, Petrus de Vinea im Königreich Sizilien. Zu Ursprung und Genese der

Briefsammlung, in «Mitteilungen des Instituts für Österreichische

Geschichtsforschung», 123 (2015), pp. 30-48.

G. Todeschini, La banca e il ghetto. Una storia italiana, Roma-Bari 2016.

S. Tognetti, Le compagnie mercantili-bancarie toscane e i mercati finanziari europei tra metà XIII e metà XVI secolo, in «Archivio storico italiano», 173 (646), pp. 687-717.

F. Tollemache, Orare, in ED, 4.

G. Tomazzoli, Nova quaedam insita mirice transsumptio: il linguaggio figurato tra le artes poetriae e Dante, in Le poetriae del medioevo latino: modelli, fortuna, commenti, a cura di G. C. Alessio, D. Losappio, Venezia 2018, pp. 257-296.

N. Tonelli, La canzone montanina di Dante Alighieri (Rime 15): nodi problematici di un commento, in «Per leggere», 19 (2010), pp. 7-36.

$\mathrm{N}$. Tonelli, Rileggendo le rime di Dante secondo l'edizione e il commento De Robertis: il libro delle canzoni, in «Studi e problemi di critica testuale», 73 (2006), pp. 9-59.

$\mathrm{N}$. Tonelli, «Tre donne», il «Convivio» e la serie delle canzoni, in Tre donne intorno al cor mi son venute, Madrid 2007, pp. 51-71.

F. Torraca, recensione a Zenatti, Dante e Firenze, in «Bullettino della Società Dantesca Italiana», 10 (1903), pp. 139-160.

J.-P. Torrell, Recherches sur la théorie de la prophétie au Moyen Âge, XII $-X I V^{e}$ siècles, Fribourg 1992.

A. Torri, Su l'epistolario di Dante Allighieri impresso a Livorno nel 1842-43: dichiarazione e protesta dell'Editore verso un bibliografo francese, Pisa 1848.

P. Toynbee, A Mispunctuation in the title of Dante's Letter to the Emperor Henry VII, in «Bulletin italien», 18 (1918), pp. 111-113 (poi in Toynbee, Dante Studies, pp. 15-18).

P. Toynbee, Dante Studies, Oxford 1921.

P. Toynbee, History of the letters of Dante from the fourteenth century to the present day, in The thirty-sixth annual report of the Dante Society, Cambridge (Mass.) $1919^{2}$.

R. Trachsler, Moult obscure parleüre. Quelques observations sur la prophétie médiévale, in Moult obscures paroles. Études sur la prophétie médiévale, a cura di R. Trachsler, Paris 2007, pp. 7-14.

R. C. Trexler, Public Life in Renaissance Florence, New York 1980.

C. Tripodi, Gli Spini tra XIV e XV secolo. Il declino di un antico casato fiorentino, Firenze 2013.

C. Troya, Del Veltro allegorico di Dante, Firenze 1826.

A.-M. Turcan Verkerk, La théorisation progressive du cursus et sa terminologie entre le $\mathrm{XI}^{e}$ et la fin du XIVe siècle, in «Archivum latinitatis medii aevi Bullettin Du Cange», 73 (2015), pp. 179-201.

A.-M. Turcan-Verkerk, La théorie des quatre styles: une invention de Jean de Garlande, in «Archivum Latinitatis Medii Aevi Bulletin Du Cange», 66 (2008), pp. 167-187.

W. Ullmann, The Development of the Medieval Idea of Sovereignty, in «The English Historical Review», 64, no. 250 (1949), pp. 1-33.

M. Vallerani, La giustizia pubblica medievale, Bologna 2006.

A. Vallone, Note sul testo e sulla pubblicazione della Commedia, in La critica dantesca nel Settecento, Firenze, 1961, pp. 65-76 (già in «Giornale Italiano di filologia», 12 [1959]).

A. Vallone, Studi sulla Divina Commedia, Firenze, 1955, pp. 3-18. 
G. M. Varanini, Appunti sull'Eloquium super arengis del notaio veronese Ivano di Bonafine «de Berinzo» (1311 c.), in «Italia medioevale e umanistica», 50 (2009, ma 2011), pp. 99121.

G. M. Varanini, Archivi di famiglie aristocratiche nel Veneto del Trecento e Quattrocento. Appunti, in Un archivio per la città, Atti della giornata di studi sugli Archivi di famiglia (Vicenza 4 aprile 1998), a cura di L. Marcadella, Vicenza 1999, pp. 24-38.

G. M. Varanini, Cancellerie signorili trecentesche dell'Italia settentrionale. Tra notariato $e$ "proto-umanesimo", in L'art au service du prince. La politique monumentale, artistique et culturelle des États princiers et seigneuriaux: paradigme italien, expérience européenne (vers 1250-vers 1550), a cura di E. Crouzet Pavan, J. C. Maire Vigueur, Roma 2015, pp. 355-376.

G. M. Varanini, “Corte”, cancelleria, cultura cittadino-comunale nella Verona del primo Trecento, in Dante a Verona 2015-2021, a cura di E. Ferrarini, P. Pellegrini,

S. Pregnolato, Ravenna 2018, pp. 9-24.

G. M. Varanini, Della Scala Bartolomeo, in DBI, 47 (1989).

G. M. Varanini, I notai e la signoria cittadina. Appunti sulla documentazione dei Bonacolsi di Mantova fra Duecento e Trecento (rileggendo Pietro Torelli), in Scritture e potere.

Pratiche documentarie e forme di governo nell'Italia tardomedievale (XIV-XV secolo), a cura di I. Lazzarini, in «Reti medievali. Rivista», 9 (2008), pp. 1-54.

G. M. Varanini, La documentazione delle signorie cittadine italiane tra Duecento e Trecento e l'Eloquium super arengis del notaio veronese Ivano di Bonafine «de Berinzo», in Chancelleries et chanceliers des princes à la fin du Moyen Âge, Actes de la table ronde de Chambéry, 5 et 6 octobre 2006, sous la direction de G. Castelnuovo, O. Mattéoni, Chambéry 2011, pp. 53-76.

G. M. Varanini, Nogarola, Bailardino, in DBI, 78 (2013), pp. 678-679.

G. M. Varanini, Reclutamento e circolazione dei podestà fra governo comunale e signoria cittadina: Verona e Treviso, in I podestà dell'Italia comunale, I, Reclutamento e circolazione degli ufficiali forestieri (fine XII sec.-metà XIV sec.), a cura di J.-C. Maire Vigueur, Roma 2000, pp. 169-201.

M. Vattasso, I codici petrarcheschi della Biblioteca Vaticana, Roma 1908.

E. M. Vecchi, «Ad pacem et veram et perpetuam concordiam devenerunt». Il cartulario del notaio Giovanni di Parente di Stupio e l'instrumentum pacis del 1306, in «Giornale storico della Lunigiana e del territorio lunense», 59 (2008), pp. 69-194.

G. Velli, Il Dante di Francesco Petrarca, in «Studi petrarcheschi», n.s. 2 (1985), pp. 185-99.

G. B. Verci, Storia della Marca Trivigiana e Veronese, Venezia 1786-1791.

C. Villa, Appunti danteschi: cronache "curiali fra DVE e Monarchia, in «Giornale storico della Letteratura italiana», 194 (2017), pp. 44-58.

C. Villa, Dante lettore di Orazio, in Dante e la «bella scola» della poesia, a cura di A. Iannucci, Ravenna 1993, pp. 87-106.

C. Villa, Dante fra due conclavi (luglio 1314-giugno 1316): per un restauro storicoconservativo della lettera ai cardinali «Apostolica Sede pastore vacante», in "Studi Danteschi», 80 (2015), pp. 1-21.

C. Villa, Il vicario imperiale, il poeta e la sapienza di Salomone: pubblicistica politica e poetica nell'epistola a Cangrande (con una postilla per re Roberto e donna Berta)/1, in «L'Alighieri», 47 (2016), pp. 19-39.

C. Villa, La testa del chiodo e il furore di Dante: "sine retractatione rivantur" (Ep. VI, 6, 26), in «Filologia mediolatina», 26 (2019, c.d.s.). 
C. Villa, L'epistola a Cangrande, la scomunica dello Scaligero e la bozza "Ne pretereat", in «Giornale storico della letteratura italiana», 196 (2019, c.d.s.).

C. Villa, L'epistola di Dante ai cardinali (post 8 settembre 2014-ante 28 giugno 2016) e la Constitutio "Ubi periculum", in «Giornale storico della letteratura italiana», 195 (2018, c.d.s.).

C. Villa, Un oracolo e una ragazza: Dante fra Moroello e la gozzuta alpigina, in Dai pochi ai molti. Studi in onore di Roberto Antonelli, a cura di P. Canettieri, A. Punzi, 2014, vol. II, pp. 1787-1798.

C. Villa, «Per le nove radici d'esto legno». Pier della Vigna, Nicola della Rocca (e Dante): anamorfosi e riconversione di una metafora, in «Strumenti critici», 6 (1991), pp. 131-144.

C. Villa, Un oracolo e una ragazza. Dante fra Moroello e la gozzuta alpigina, in Dai molti ai pochi. Studi in onore di Roberto Antonelli, a cura di P. Canettieri, A. Punzi, Roma 2014, vol. II, pp. 1787-1798.

C. Villa, M. Petoletti, Teatro Ambrosiano, in Nuove ricerche su codici in scrittura latina dell'Ambrosiana. Atti del Convegno, Milano, 6-7 ottobre 2005, a cura di M. Ferrari, M. Navoni, Milano 2007, pp. 135-152.

P. Villari, Dante, gli esuli fiorentini e Arrigo VII (1888-1889), in Villari, I primi due secoli della Storia di Firenze, Firenze 1898 (2 $2^{\mathrm{a}}$ ed.), vol. I, pp. 145-184.

G. Vinay, A proposito della lettera di Dante ai cardinali, in «Giornale storico della letteratura italiana», 135 (1958), pp. 71-80.

G. Vinay, Riflessioni per un centenario (1265-1965), in «Studi medievali», $3 / 6$ (1965), pp. 1166, poi parzialmente rist. in Peccato che non leggessero Lucrezio. Riletture proposte da C. Leonardi, Spoleto 1989, pp. 379-434.

M. E. Viora, A proposito del vicariato imperiale in Italia attribuito dai Pontefici a Roberto d'Angiò, in «Annali triestini di diritto, economia e politica», 13 (1942), pp. 175-187.

V. Vitale, Il dominio della parte guelfa in Bologna (1280-1327), Bologna 1901 (rist. anastatica Sala Bolognese 1978).

P. Viti, Francesco da Montepulciano, in DBI, 49 (1997).

P. Viti, Due commedie umanistiche pavesi. Ianus sacerdos, Repetitio magistri Zanini coqui, Padova 1982.

P. von Moos, Consolatio, München 1971-1972.

P. Von Moos, Die italienische ars arengandi des 13. Jahrhunderts als Schule der Kommunikation, in Rhetorik, Kommunikation und Medialität. Gesammelte Studien zum Mittelalters, Berlin 2006, vol. II, pp. 127-152.

L. von Rockinger, Briefsteller und Formelbücher des eilften bis vierzehnten Jahrhunderts, München 1863.

F. X. von Wegele, Albrecht I (römisch-deutscher-könig), in Allgemeine Deutsche Biographie, Leipzig 1875-1910, vol. I (1875), pp. 224-27.

L. Wahlgren, The Letter Collection of Peter of Blois: Studies in the Manuscript Tradition, Göteborg 1993.

D. Waley, Colonna, Giacomo, in DBI, 27 (1982).

D. Waley, The army of the Florentine republic from the twelfth to the fourteenth century, in Florentine studies. Politics and society in renaissance Florence, a cura di N. Rubinstein, London 1968, pp. 70-108.

I. Walter, Carlo Martello d'Angiò, re d'Ungheria, in DBI, 20 (1977).

J. O. Ward, Rhetorical Theory and the Rise and Decline of Dictamen in the Middle Ages and Early Renaissance, in «Rhetorica», 19 (2001), pp. 175-223.

M. Weber, La scienza come professione. La politica come professione, Torino 1994. 
C. Wickham, The Mountains and the City, Oxford 1988.

P. H. Wicksteed, E. G. Gardner, Dante and Giovanni del Virgilio. Including a critical edition of the text of Dante's "Eclogae latinae" and of the poetic remains of Giovanni del Virgilio, Westminster 1902.

H. Wieruszowski, Politics and Culture in Medieval Spain and Italy, Roma 1971.

R. Witt, Medieval ars dictaminis and the beginnings of humanism: a new construction of the problem, in «Renaissance Quarterly», 35/1 (1982), pp. 1-35 (rist. anastica in R. Witt, Italian Humanism and Medieval rhetoric, Aldershot 2001, t. I, pp. 1-35).

H. Witte, Karl Witte ein Leben für Dante, Hamburg 1971.

K. Witte, Dante Alighieri's Lyrische Gedichte, Leipzig 1842.

K. Witte, Dante Forschungen I, Heilbronn 1869.

K. Witte, Neu aufgefundene Briefe des Dante Allighieri, in «Blätter für literarische Unterhaltung», pp. 149-151 (1838), (poi in Witte, Dante-Forschungen. Altes und neues, I, Heilbronn 1877, pp. 473-499).

K. Witte, Torris Ausgabe von Dantes Briefen, in «Blätter für literarische Unterhaltung», p. 341 (poi in Dante Forschungen. Altes und neues, I, pp. 488-499).

K. Witte, Über das Missverständnis Dantes (poi in Dante Forschungen. ALtes und neues, I, Heilbronn 1869).

J. R. Woodhouse, Dante and Governance, Oxford 1997.

C. N. S. Woolf, Bartolus of Sassoferrato: His Position in the History of Medieval Political Thought, Cambridge 1913.

W. Ysebaert, Medieval letters and letter collections as historical sources: methodological questions, reflections and research perspectives (6th-14th centuries), in «Studi medievali», III/50 (2009), pp. 41-73.

G. Yver, Le commerce et les marchand dans l'Italie méridionale au XIIIè et au XIVè siècle, Paris 1902.

M. Zabbia, Dalla propaganda alla periodizzazione. L'invenzione del "buon tempo antico", in «Bullettino dell'Istituto Storico Italiano per il Medio Evo», 107 (2005), pp. 247-282.

M. Zabbia, Il Regno nelle cronache comunali prima e dopo la battaglia di Benevento, in Suavis terra, inexpugnabile castrum. L'alta Terra di lavoro dal dominio svevo alla concquista angioina, a cura di F. Delle Donne, Arce 2007, pp. 115-131.

G. Zaccagnini, Cino da Pistoia: studio biografico, Pistoia 1918.

V. Zaccaria, Per il testo delle "Genealogie deorum gentilium", in «Studi sul Boccaccio», 16 (1987), pp. 179-240.

V. Zaccaria, Boccaccio narratore, storico, moralista e mitografo, Firenze 2001.

S. Zamponi, Nello scrittoio di Coluccio Salutati: il Lattanzio Placido forteguerriano, in Tra libri e carte. Studi in onore di Luciana Mosiici, a cura di G. Savino, T. De Robertis, Firenze 1998, pp. 549-592.

S. Zamponi, Un Lattanzio Placido scritto da un gruppo di copisti diretti da Salutati (scheda del ms. Pistoia, Biblioteca Comunale Forteguerriana, A.45), in Coluccio Salutati e l'invenzione dell'Umanesimo, a cura di T. De Robertis, G. Tanturli, S. Zamponi, Firenze 2008, pp. 338-341.

S. Zanke, Johannes 22., Avignon und Europa: das politische Papsttum im Spiegel der kurialen Register (1316-1334), Leiden 2013.

K. Zelzer, Zur Überlieferung der Rhetorik Ad Herennium, in «Wiener Studien», n.s. 16 (1982), pp. 183-211.

O. Zenatti, Dante e Firenze. Prose antiche, Firenze 1902. 
C. Zey, Zur Einführung, in Mächtige Frauen? Königinnen und Fürstinnen im europäischen Mittelalter (11.-14. Jahrhundert). Zur Einführung, a cura di C. Zey, in «Vorträge und Forschungen», 81 (2015), pp. 9-33.

N. Zingarelli, La vita, i tempi e le opere di Dante, Milano 1931.

J. M. Ziolkowski, Theories of obscurity in the Latin tradition, in «Mediaevalia. A journal of medieval studies», 19 (1993), pp. 101-70.

G. Zippel, Nicolò Niccoli. Contributo alla storia dell'Umanismo, con un'appendice di documenti, Firenze 1890.

A. Zorzi, La faida Cerchi-Donati, in Zorzi, La trasformazione di un quadro politico. Ricerche su politica e giustizia a Firenze dal Comune allo Stato territoriale, Firenze 2008, pp. 95-120.

A. Zorzi, Ripensando i vicariati imperiali e apostolici, in Signorie italiane e modelli monarchici (secoli XIII-XV), a cura di P. Grillo, Roma 2013, pp. 19-43.

R. Zucchi, Ottonello Descalzi e la fortuna del "De viris illustribus", in «Italia medioevale e umanistica», 17 (1974), pp. 469-490.

H. Zug Tucci, Henricus coronatur corona ferrea in Il viaggio di Enrico VII in Italia, a cura di M. Tosti Croce, Città di Castello 1993, pp. 29-42.

\section{Banche dati on-line}

Alim, Archivio della latinità italiana del Medioevo: http://alim.unisi.it.

BREPOLiS, insieme di archivi testuali mediolatini: http://apps.brepolis.net/BrepolisPortal/ default.aspx.

DanteSearch: corpus delle opere volgari e latine di Dante lemmatizzate con annotazione morfologica e sintattica: http://www.perunaenciclopediadantescadigitale.eu:8080/ dantesearch/.

Dartmouth Dante Project: a searchable full-text database containing more than seventy commentaries on Dante's Divine Comedy: https://dante.dartmouth.edu/search.php. 